\title{
Frontal EEG asymmetry during symptom provocation predicts subjective responses to intrusions in survivors with and without PTSD
}

Citation for published version (APA):

Meyer, T., Quaedflieg, C. W. E. M., Weijland, K., Schruers, K., Merckelbach, H., \& Smeets, T. (2018). Frontal EEG asymmetry during symptom provocation predicts subjective responses to intrusions in survivors with and without PTSD. Psychophysiology, 55(1), [12779]. https://doi.org/10.1111/psyp.12779

Document status and date:

Published: 01/01/2018

DOI:

10.1111/psyp. 12779

Document Version:

Publisher's PDF, also known as Version of record

Document license:

Taverne

Please check the document version of this publication:

- A submitted manuscript is the version of the article upon submission and before peer-review. There can be important differences between the submitted version and the official published version of record.

People interested in the research are advised to contact the author for the final version of the publication, or visit the DOI to the publisher's website.

- The final author version and the galley proof are versions of the publication after peer review.

- The final published version features the final layout of the paper including the volume, issue and page numbers.

Link to publication

\footnotetext{
General rights rights.

- You may freely distribute the URL identifying the publication in the public portal. please follow below link for the End User Agreement:

www.umlib.nl/taverne-license

Take down policy

If you believe that this document breaches copyright please contact us at:

repository@maastrichtuniversity.nl

providing details and we will investigate your claim.
}

Copyright and moral rights for the publications made accessible in the public portal are retained by the authors and/or other copyright owners and it is a condition of accessing publications that users recognise and abide by the legal requirements associated with these

- Users may download and print one copy of any publication from the public portal for the purpose of private study or research.

- You may not further distribute the material or use it for any profit-making activity or commercial gain

If the publication is distributed under the terms of Article $25 \mathrm{fa}$ of the Dutch Copyright Act, indicated by the "Taverne" license above, 


\title{
Frontal EEG asymmetry during symptom provocation predicts subjective responses to intrusions in survivors with and without PTSD
}

\author{
Thomas Meyer1,2 | Conny W. E. M. Quaedflieg2,3 | Kim Weijland ${ }^{2}$ | \\ Koen Schruers $^{4,5}$ | Harald Merckelbach ${ }^{2}$ | Tom Smeets ${ }^{2}$
}

${ }^{1}$ Behavioural Science Institute, Radboud University Nijmegen, Nijmegen,

The Netherlands

${ }^{2}$ Clinical Psychological Science, Maastricht University, Maastricht, The Netherlands

${ }^{3}$ Cognitive Psychology, University of Hamburg, Hamburg, Germany

${ }^{4}$ Mental Health and Neuroscience, Maastricht University, Maastricht, The Netherlands

${ }^{5}$ Centre for Learning and Experimental Psychology, University of Leuven, Leuven, Belgium

\section{Correspondence}

Thomas Meyer, Department of Experimental Psychopathology and Treatment, Behavioural Science Institute, Radboud University Nijmegen,

P.O. Box 9104, 6500 HE Nijmegen,

The Netherlands.

Email: t.meyer@bsi.ru.nl

Funding information

Netherlands Organization for Scientific Research (NWO), Grant number: 056-25011 to TS.

\begin{abstract}
Studies suggest that frontal alpha asymmetry is closely linked to psychological adjustment following stressful experiences, such that more left-sided frontal activation during symptom provocation might predict lower levels of posttraumatic stress disorder (PTSD). Here, we tested whether frontal asymmetry at rest and during exposure to neutral, positive, negative, and trauma-related images would be associated with PTSD, and particularly with characteristic reexperiencing symptoms. Symptoms were assessed in trauma victims with $(n=24)$ and without PTSD $(n=15)$, using both retrospective measures and 1-week ambulatory assessments with a diary and a smartphone. While resting frontal asymmetry was unrelated to all retrospective measures, left-sided activation in response to the negative picture correlated with lower levels of psychopathology. Left-sided activation in the trauma-related picture condition was more specifically associated with less emotionally intense intrusions and responses to viewing the picture, even when corrected for other symptoms of psychopathology. These effects tended to increase when participants with possible overreporting tendencies were removed from the analyses. Moreover, trauma victims without PTSD (i.e., relatively more resilient individuals) displayed higher left-sided frontal activation in response to the negative picture, also when compared with a third group of healthy, trauma-free individuals $(n=15)$. Our findings suggest that statedependent changes in frontal asymmetry could serve as a biological marker of PTSD symptoms and could eventually be used for diagnostic purposes or as a target for neuromodulation interventions. Future studies should establish whether this marker can serve as an early predictor of psychopathology in recently traumatized individuals.
\end{abstract}

\section{KE Y W OR D S}

diary, frontal alpha asymmetry, intrusions, posttraumatic stress disorder, symptom provocation

\section{1 | INTRODUCTION}

A small, yet nontrivial proportion of individuals who have experienced aversive life events develop trauma-related psychopathology, such as posttraumatic stress disorder (PTSD). These trauma victims suffer from severe reexperiencing symptoms (e.g., intrusions, nightmares), avoidance of cues related to the trauma, altered mood and cognition, as well as exaggerated general arousal and reactivity (American Psychiatric Association, 2013). Since the diagnosis of PTSD essentially depends on self-report (Rosen \& Lilienfeld, 2008) and its symptoms are only modestly related to objective trauma severity (Brewin, Andrews, \& Valentine, 2000; Kessler, Sonnega, Bromet, Hughes, \& Nelson, 1995; McNally \& 
Robinaugh, 2011), researchers and clinicians have been searching for biological markers of psychological adjustment to stress and trauma. The present study focused on so-called frontal asymmetry as a potential biological indicator of PTSD symptoms following trauma exposure.

Frontal asymmetry is a widely studied EEG biomarker that refers to a hemispheric difference in alpha band power (typically $8-13 \mathrm{~Hz}$ ) above the frontal cortex (right minus left). Given alpha's inverse relationship with brain activity (e.g., Pfurtscheller, Stancak, \& Neuper, 1996), more positive asymmetry scores are conventionally interpreted as reflecting more left-sided frontal brain activity (Coan \& Allen, 2004). Measured across several minutes in resting individuals, this marker has been shown to possess high internal consistency, as well as good test-retest reliabilities (Towers \& Allen, 2009). For decades, evidence has been accumulating to suggest that more left-sided frontal activity is associated with stronger approach motivation (e.g., Tomarken, Davidson, Wheeler, \& Doss, 1992), behavioral activation (e.g., Quaedflieg, Meyer, Smulders, \& Smeets, 2015; Wacker, Chavanon, Leue, \& Stemmler, 2008), enhanced affect and stress regulation (e.g., Koslov, Mendes, Pajtas, \& Pizzagalli, 2011), psychological well-being (e.g., Urry et al., 2004), as well as with fewer symptoms of mood and anxiety disorders (Thibodeau, Jorgensen, \& Kim, 2006). Based on these findings (for reviews, see Coan \& Allen, 2004; Harmon-Jones, Gable, \& Peterson, 2010), frontal asymmetry has long been regarded as a promising indicator of psychological resilience and (inversely) vulnerability to develop psychopathology.

Despite these promising indications, the frontal asymmetry literature is inconsistent. For example, several studies failed to replicate the relationship between frontal asymmetry at rest with depression (e.g., Bruder et al., 1997; Reid, Duke, \& Allen, 1998). Moreover, for PTSD, resting state frontal asymmetry has only little or even no predictive value across studies (for review, see Meyer, Smeets et al., 2015). In part, these inconsistencies might be due to methodological differences affecting the sensitivity and reliability of the EEG measurement (e.g., length of recording and reference scheme; see Allen, Coan, \& Nazarian, 2004; Allen \& Reznik, 2015; Hagemann, 2004; Hagemann, Naumann, Thayer, \& Bartussek, 2002). However, there also is an emerging consensus that frontal asymmetry has no ubiquitous and straightforward association with mental health outcomes (Allen \& Reznik, 2015; Coan, Allen, \& McKnight, 2006; Meyer, Smeets et al., 2015), for two major reasons. First and most importantly, the associations with motivational or mental health outcomes appear to depend on the affective-motivational context during which frontal asymmetry is measured (Coan et al., 2006). For instance, several studies (e.g., Stewart, Coan, Towers, \& Allen, 2011, 2014) have found that relatively lower left-sided activation in response to emotional challenges, but not left-sided activity at rest, predicted current or past levels of depression (for review, see Allen \& Reznik, 2015). Similarly, for PTSD, Rabe and colleagues found an association between left-sided activation in response to viewing a trauma-related picture and fewer PTSD symptoms (Rabe, Beauducel, Zöllner, Maercker, \& Karl, 2006; Rabe, Zöllner, Beauducel, Maercker, \& Karl, 2008). Thus, in line with a so-called capability model of frontal asymmetry (see Coan et al., 2006), changes in frontal asymmetry that correlate with affective-motivational states appear to be associated with mental health outcomes, and more robustly so than frontal asymmetry at rest.

Second, a frequent limitation in psychiatric research examining biomarkers like frontal asymmetry is that studies have focused on patient groups defined by their diagnostic status rather than their predominant symptoms (Nusslock, Walden, \& Harmon-Jones, 2015; Schmidt, 2015). This argument is especially relevant to PTSD, since this syndrome comprises fear, mood, and general distress-related symptoms that are shared with other mood and anxiety disorders (American Psychiatric Association, 2013; Forbes et al., 2012; Zoellner, Pruitt, Farach, \& Jun, 2014). Following the view that frontal asymmetry is closely linked to state and trait motivational direction (Nusslock et al., 2015), associations can thus be expected with mood and fear-related PTSD symptoms that are characterized by deficient approach and exaggerated withdrawal motivation, respectively.

Meanwhile, motivational direction may play only a limited role in PTSD reexperiencing symptoms, including dissociative amnesia and flashback memories, that are thought to be unique in PTSD (Brewin, 2011; Bryant, O’Donnell, Creamer, McFarlane, \& Silove, 2011) and may depend on specific memory functions that make traumatic memories more or less accessible (e.g., Bisby, King, Brewin, Burgess, \& Curran, 2010; Meyer et al., 2013). Moreover, it has been proposed that anxious arousal is associated with relatively higher right parietal activation, whereas anxious apprehension would be associated with frontal asymmetry (Heller, Nitschke, Etienne, \& Miller, 1997; Nitschke, Heller, Palmieri, \& Miller, 1999). Accordingly, frontal asymmetry might not display specific relationships with PTSD symptoms related to hyperarousal (e.g., the emotional intensity of traumatic memories, sweating, tachycardia; Rubin, Boals, \& Berntsen, 2008), whereas associations with cognitive-emotional reactions to the activation of traumatic memories can be expected (including exaggerated negative mood responses, and strong negative appraisal and rumination; Steil \& Ehlers, 2000). Notably, these factors are believed to perpetuate and maintain PTSD symptoms in trauma victims (Clohessy \& Ehlers, 1999).

Based on these considerations, the present study aimed to further investigate the association of frontal asymmetry 
with PTSD symptoms. We had a particular interest in exploring possible associations with reexperiencing symptoms and exaggerated emotional and cognitive reactions to the activation of trauma memories, which are relatively understudied components of this disorder (Brewin, 2015; see also Meyer, Otgaar, \& Smeets, 2015). For this purpose, we recruited trauma victims with PTSD and trauma victims without PTSD, and assessed PTSD symptoms with questionnaires, next to symptoms of depression, anxiety, and general psychopathology. Since ambulatory measurements might capture reexperiencing symptoms more accurately than retrospective scales (for a review, see Chun, 2016), we used diaries and smartphones to assess the occurrence of intrusive memories and how people reacted to them. In addition, we included a self-report scale to assess the tendency to overreport symptoms, which may obscure associations between frontal asymmetry and symptoms, particularly in analyses that rely on retrospection (Merckelbach \& Smith, 2003). In line with Rabe, Beauducel et al. (2006), frontal asymmetry was measured at rest, as well as in an emotion provocation task during which participants viewed a neutral, a negative, a positive, and a trauma-related picture. This setup made it possible to contrast emotional conditions varying in valence (negative, positive) and idiosyncratic meaning (traumarelated, unrelated) with the neutral condition, which was intended as a baseline. Furthermore, the task allowed us to assess subjective responses to viewing the trauma-related image (i.e., emotional intensity, rumination, experience of a physical reaction, and distress).

Our basic hypothesis was that relatively more left-sided frontal activity would be associated with fewer PTSD symptoms. Based on prior frontal asymmetry studies in PTSD (Meyer, Smeets et al., 2015; Rabe, Beauducel et al., 2006; Rabe et al., 2008), we explored this hypothesis for resting frontal asymmetry and for activation asymmetry in response to emotional provocation, expecting that asymmetry in the trauma-related and negative conditions would be the best predictors of PTSD symptoms. Since reexperiencing symptoms are thought to be specific to PTSD, we expected that potential associations with emotional and cognitive reactions to intrusions and to viewing the trauma-related picture would remain significant when corrected for symptoms of other disorders and for symptom overreporting tendencies. Finally, for the purpose of group-level analyses, we also recruited a comparison group of healthy participants who had never been exposed to psychological trauma. Based on prior findings by Rabe, Beauducel et al. (2006), we expected stronger left-sided activation in response to viewing the trauma picture in trauma-exposed participants without PTSD (i.e., relatively more resilient individuals), and weaker left-sided activation in participants with PTSD (i.e., nonresilient individuals), as compared with nontrauma-exposed controls.

\section{2 | METHOD}

\section{1 | Participants}

Forty trauma survivors and 15 healthy participants without trauma exposure enrolled in this study. An overview of the different types of trauma and their frequencies, as well as demographic information and sample characteristics, can be found in the first two tables in the following sections. All participants were required to be aged between 18 and 60 years, be proficient in Dutch, and have normal or corrected-tonormal vision. Trauma survivors were recruited via advertisements and among trauma victims seeking treatment at local psychiatric outpatient clinics (RIAGG Maastricht and Academic Anxiety Center Mondriaan/PsyQ in Maastricht, The Netherlands). For these participants, an inclusion criterion was the presence of a potentially traumatic experience (i.e., criterion A1 for PTSD according to the DSM-IV; American Psychiatric Association, 2000), as established using a Structured Clinical Interview for DSM-IV for Axis-I disorders (SCID-I; First, Spitzer, Gibbon, \& Williams, 2002). The presence of a PTSD diagnosis was neither an inclusion nor an exclusion criterion. However, participants who had previously been diagnosed with PTSD and who had recovered (e.g., following treatment for PTSD) were excluded. Also, we excluded participants with traumatic experiences that referred to an extended time period (e.g., childhood abuse lasting several years) rather than distinct episodes, because our emotion provocation task required the identification of a distinct traumatic memory that could be activated with a single picture stimulus. Furthermore, the following exclusion criteria were employed: (a) traumatic experiences in the past 6 months, (b) current psychotherapy, (c) current or lifetime diagnosis of psychotic or bipolar disorder, (d) current substance abuse or addiction, (e) psychoactive medication unless medication had been stable for 3 months, and (f) a history of head injury or neurological problems (e.g., epilepsy). Healthy participants without trauma exposure were required to be free of any traumatic experiences, and, in addition to the above-mentioned exclusion criteria, had to be free of any current Axis-I disorder according to the DSM-IV, as established during a MiniInternational Neuropsychiatric Interview (MINI; Sheehan et al., 1998). All participants provided written informed consent. This study was approved by the standing ethical committee of the Faculty of Psychology and Neuroscience, Maastricht University, The Netherlands.

\subsection{1 | Recruitment and diagnostic procedures}

To recruit eligible trauma survivors, we screened potential participants who were identified by the intake staff at local psychiatric outpatient clinics and respondents to the 
advertisements. Candidates were initially screened for inclusion and exclusion criteria by telephone, whereby biographical data, a short description and approximate date of traumatic experiences, reasons for past or present psychological, psychiatric, or medical treatments, medication, as well as the frequency of tobacco, alcohol, and drug use were obtained. During this interview, participants were also comprehensively informed about all parts of this study. For candidates who reported at least one traumatic experience, eligibility for participation was further based on a SCID-I (First et al., 2002), which was administered during an individual diagnostic session by the intake staff at the psychiatric outpatient clinics, or by Master or PhD level psychology students who had previously received an extensive SCID training. Next to recording the presence of Axis-I disorders, this interview was used to verify the presence of a traumatic experience according to the PTSD criterion A1 in the DSMIV (American Psychiatric Association, 2000), ${ }^{1}$ and to record trauma type and frequency, as well as the time passed since the traumatic experience(s).

Among 196 candidates who were referred from the psychiatric clinics, reasons for exclusion were index traumatic experiences that did not fulfill DSM-IV criteria or referred to an extended traumatic period $(n=49)$, not fulfilling the age criterion $(n=37)$, current psychotherapy $(n=37)$, diagnosed substance abuse or addiction $(n=18)$, PTSD in remission $(n=5)$, neurological or medical problems $(n=4)$, and lacking proficiency in Dutch $(n=2)$. Finally, 23 declined their participation or discontinued the contact, leaving 21 who enrolled in the trauma survivor groups.

In addition, at least 133 individuals responded to the advertisements, 76 indicating the presence of a possible traumatic experience (a small part of these data was lost and is excluded from these statistics). Among this latter group, reasons for exclusion were index traumatic experiences that did not fulfill DSM-IV criteria or referred to an extended traumatic period $(n=10)$, the age criterion $(n=9)$, neurological or medical problems $(n=5)$, psychotic or bipolar disorders $(n=2)$, substance abuse $(n=1)$, and lacking proficiency in Dutch $(n=1)$. Finally, 29 declined their participation or discontinued the contact, leaving 19 who enrolled in this study.

Potential participants who did not report a traumatic experience were considered for participation if they could be matched to one of the trauma-exposed participants in terms of gender, age (difference $<4$ years), and highest completed education level according to the Dutch system (lower secondary, upper secondary, postsecondary, or higher education). They were invited to a telephone interview with the

\footnotetext{
${ }^{1}$ As can be seen in Table 1, the large majority of included participants also fulfilled criteria A1 of the DSM-V (American Psychiatric Association, 2013).
}

MINI (Sheehan et al., 1998) to establish eligibility for the healthy nontrauma-exposed group.

\subsection{2 | Diagnostic groups}

For group analyses, we divided the trauma survivors into those with a PTSD diagnosis and those without, based on the SCIDI outcomes. One participant diagnosed with PTSD endorsed a considerable number of items on the Structured Inventory of Malingered Symptomatology (SIMS; total score $=27 ;>3 S D$ higher than the sample mean; cf. Table 2), while performing below-chance level on a visual search task (a contextual cueing paradigm with nonemotional search displays; Meyer et al., 2013; data not included here) despite repeated instructions (accuracies below the 50\% chance level in 23/30 blocks). As this response pattern is indicative of deliberate symptom overreporting and task underperformance, this particular participant was removed from all analyses. Among the remaining participants diagnosed with PTSD $(n=24)$, some also had diagnoses of a current mood $(n=11)$ and/or anxiety disorder $(n=7)$, somatoform disorder $(n=3)$, eating disorder $(n=1)$, ADHD $(n=1)$, a mood disorder in partial or complete remission $(n=5)$, and/or an eating disorder in remission $(n=2)$. Among the trauma survivors without PTSD (i.e., a relatively more resilient subgroup; $n=15)$, some also were diagnosed with a mood disorder $(n=1)$, anxiety disorder $(n=3)$, or an anxiety disorder in remission $(n=1)$.

\subsection{3 | Incomplete data}

One participant diagnosed with PTSD did not return for the second session, and one participant in the healthy control group terminated participation prematurely. These two individuals were excluded from correlational analyses regarding symptoms of psychopathology. However, we retained their EEG and response data for group-level analyses. Data from two questionnaires (BDI-II and SIMS) from one other participant (healthy control participant) were missing, as were the data from one questionnaire (SIMS) of one trauma victim with PTSD.

\section{2 | Trauma-related symptoms}

\subsection{1 | Retrospective assessment}

We used the PTSD Checklist Civilian version (PCL; Blanchard, Jones-Alexander, Buckley, \& Forneris, 1996). It consists of 17 items that require the respondent to indicate the frequency of experiencing DSM-IV (American Psychiatric Association, 2000) symptoms of PTSD in the past month on 5-point scales $(1=$ not at all, $5=$ extremely $)$. The sum score $(\alpha=.95)$ serves as a total PTSD severity score. In parallel, we used the selfreported PTSD Symptom Scale (PSS-SR; Foa, Riggs, Dancu, 
\& Rothbaum, 1993), which consists of four reexperiencing items $(\alpha=.87)$, seven avoidance items $(\alpha=.85)$, and six hyperarousal items, $(\alpha=.84$; total score $\alpha=.93)$.

As a self-report measure of cognitive and affective responses to the occurrence of intrusions, we used the Response to Intrusions Questionnaire (RIQ) developed by Clohessy and Ehlers (1999) and adapted in Dutch by Smets, Wessel, Schreurs, and Raes (2012). It consists of two subscales, whereby the first assesses the frequency of ruminating about the content of intrusions on eight items (e.g., "I dwell on how the event could have been prevented"; $\alpha=.81$ ), requiring responses on a 4 -point scale $(1=$ never, $4=$ all the time). The second subscale measures negative appraisals of intrusions (e.g., "The fact that I experience intrusions means that I am going crazy"; 6 items; $\alpha=.81$ ), on 7-point scales $(1=$ strongly disagree, $7=$ strongly agree $)$. Responses are summed to provide scores for each subscale.

\subsubsection{Ambulatory assessment-intrusion diary}

We measured the occurrence of intrusions, defined as sudden, involuntary memories of traumatic experiences, and affective reactions to intrusions during a period of 7 days using a pen-and-paper diary. Similar to the diary method often used in experimental analogue studies (see Holmes, Brewin, \& Hennessy, 2004; Meyer et al., 2013), the diary had two parts. The first consisted of a structured page for each day in which participants noted the occurrence of intrusions, next to the time of waking up and going to bed, and the overall level of stress experienced during the day (not counting stress caused by the intrusions) on a scale from 0 (not stressful) to 100 (extremely stressful). There also was free space left for notes about any experiences of the day that were out of the normal range (optional). Participants were instructed to fill out the diary whenever an intrusion occurred, and at least twice a day. In the second part of the diary, participants were asked to provide details about each intrusion that they had recorded. In particular, they were asked to write down the content and trigger of the intrusion (to verify that the memory was involuntary and trauma related), and whether it was primarily based on images, thoughts, or both. Furthermore, they were asked how distressing the intrusion was, how intense the elicited emotions were, and whether they had any physical reaction associated with it (e.g., laughing, sweating, tachycardia), all rated on scales ranging from 0 (not at all) to 100 (extremely).

For our analyses, we computed the number of intrusions with an image component and those with a thought component, as well as the total frequency of intrusions. Frequency scores were logarithm-transformed prior to the analyses to correct for their strongly skewed distribution (i.e., $\ln [1+\#$
TABLE 1 Frequency of different trauma types and individualized trauma-related IAPS pictures for the emotion provocation task

\begin{tabular}{|lll|}
\hline Index trauma & Frequency & $\begin{array}{l}\text { Trauma-related picture } \\
\text { for emotion provocation } \\
\text { paradigm (International } \\
\text { Affective Picture System \#) }\end{array}$ \\
\hline Witness & 10 & $\begin{array}{l}3016,3060,3216,6313, \\
6315,9410,9903\end{array}$ \\
\hline $\begin{array}{l}\text { Death of a close } \\
\text { one }\end{array}$ & 7 & $2053,3216,3225$, \\
\hline Threat of violence & 6 & $3230,6570,9911$ \\
\hline Rape & & $6313,6315,6321$, \\
\hline Physical abuse & 4 & 6560,6561 \\
\hline Armed robbery & 4 & $6313,6315,6560$ \\
\hline Other life-threatening & 3 & $3181,6313,6315$ \\
\hline Control group & 15 & $6313,6321,6370$ \\
\hline & & $1726,6321,9903$ \\
\hline
\end{tabular}

${ }^{\mathrm{a}}$ While fulfilling criterion A1 for trauma exposure according to the DSM-IV, it is unclear for a minority $(n=3)$ whether they also fulfill DSM-V criteria for trauma exposure (i.e., death may not have been violent or accidental).

intrusions]). Distress, intensity, and physical reaction scores were averaged across all recorded intrusions for the analyses (zero was entered when no intrusion had occurred).

\subsection{3 | Ambulatory assessment-smartphone}

Complementary to the diary, we provided participants with a smartphone that was used to measure the degree to which intrusions changed affect levels referenced to baseline over a 7-day period. In order to measure baseline affect levels, participants received five messages throughout each day and were prompted to fill out an affect grid (Russell, Weiss, \& Mendelsohn, 1989); an item consisting of a single $9 \times 9$ grid, whereby respondents had to select a single field that best reflected their current level of valence on the horizontal axis (range: $1=$ unpleasant feelings, $9=$ pleasant feelings) and arousal on the vertical axis (range: $1=$ sleepiness, $9=$ high arousal). The timing of the messages was tailored to the typical waking hours of each participant, such that the first and last messages were sent between 30 and 90 min after the time of getting up, and between 90 and $30 \mathrm{~min}$ before going to sleep, respectively. The remaining three messages were equally distributed throughout the day with \pm 30-min random variation.

Whenever participants experienced an intrusion, they were asked to indicate this via the smartphone by following 
TABLE 2 Symptoms of PTSD, anxiety, depression, and overall psychopathology in the current sample

\begin{tabular}{|c|c|c|c|c|c|c|}
\hline Method & \multicolumn{3}{|l|}{ Group } & Test & \multicolumn{2}{|c|}{ Pairwise comparisons $(p)$} \\
\hline$n$ & 24 & 15 & 15 & & & \\
\hline$\%$ Female & 75.0 & 66.7 & 93.3 & $\chi^{2}(2)=3.28$ & & \\
\hline Handedness (EHI) & $76.6(36.6)$ & $44.1(80.5)$ & $80.0(28.7)$ & $F(2,51)=2.39$ & & \\
\hline PANAS-PA state & $27.5(7.7)$ & $32.0(7.6)$ & $28.1(7.2)$ & $F(2,51)=1.77$ & & \\
\hline PANAS-NA state & $20.2(8.3)$ & $13.5(6.4)$ & $11.5(1.6)$ & $F(2,51)=9.54 * * *$ & .010 & $>.99$ \\
\hline Reexperiencing & $5.7(2.9)$ & $2.2(2.4)$ & $0.6(1.0)$ & $F(2,49)=21.59 * * *$ & $<.001$ & .26 \\
\hline Avoidance & $8.3(4.9)$ & $2.4(2.7)$ & $0.5(1.2)$ & $F(2,49)=22.93 * * *$ & $<.001$ & .51 \\
\hline Hyperarousal & $10.2(3.5)$ & $4.9(3.0)$ & $1.4(1.4)$ & $F(2,49)=42.18 * * *$ & $<.001$ & .006 \\
\hline STAI-T & $54.3(8.9)$ & $38.6(13.2)$ & $32.8(4.7)$ & $F(2,49)=25.62 * * *$ & $<.001$ & .32 \\
\hline BDI-II & $23.3(9.5)$ & $8.3(9.3)$ & $2.1(3.4)$ & $F(2,48)=30.69 * * *$ & $<.001$ & .16 \\
\hline BSI score & $1.27(0.59)$ & $0.56(0.61)$ & $0.16(0.14)$ & $F(2,49)=21.53^{* * *}$ & $<.001$ & .12 \\
\hline SIMS total score & $10.8(5.1)$ & $6.1(4.4)$ & $3.2(2.6)$ & $F(2,47)=13.03 * * *$ & .007 & .29 \\
\hline
\end{tabular}

Note. Standard deviations of the mean and degrees of freedom for the statistical tests appear in parentheses. EHI = Edinburgh Handedness Inventory; PANAS = Positive and Negative Affect Schedule; PA = Positive Affect; NA = Negative Affect; PCL = PTSD Checklist (Civilian version); PSS-SR = PTSD Symptom Scale-Self-Report; STAI = State-Trait Anxiety Inventory; BDI-II = Beck Depression Inventory II; BSI = Brief Symptom Inventory; SIMS = Structured Inventory of Malingered Symptomatology.

*** $p<.001$.

a link that was provided to them. For ethical reasons, we explicitly allowed our participants to omit reporting an intrusion via the smartphone if this would be experienced as too stressful, or when the intrusion occurred at night (e.g., waking up from a nightmare). Upon following the link, they were prompted to fill out an affect grid. After 15 and $30 \mathrm{~min}$, they received two follow-up messages with another affect grid. At the same time, all baseline measurements were suppressed for a period of $3 \mathrm{~h}$.

For the analyses, we calculated the mean valence and arousal levels across all weekly baseline measurements per participant. Moreover, we averaged the valence and arousal levels following an intrusion, separately for the immediate, $+15 \mathrm{~min}$, and the $+30 \mathrm{~min}$ timings. Finally, we derived valence and arousal reactivity scores for each timing by subtracting the weekly baseline from the values at each timing. Higher reactivity scores reflect relatively increased valence and arousal in response to intrusions.

\section{3 | Resting state EEG measurement}

In line with the procedure described in Tomarken, Davidson, Wheeler, and Kinney (1992), the resting state EEG measurement consisted of eight 1-min blocks with a fixed interval of $20 \mathrm{~s}$ between blocks. In half of the blocks, participants were instructed to keep their eyes open and look straight ahead at a fixation cross, and in the other half participants had to keep their eyes closed. The beginning of each block was signaled by a single tone, and the end by a double tone. The order of open- and closed-eyes conditions was randomized for each participant, whereby each condition could not occur more than twice consecutively.

\section{4 $\mid$ Emotion provocation task}

We employed an emotion provocation task similar to the one described previously by Rabe, Beauducel et al. (2006). This task consisted of four 2-min blocks, during which participants 
viewed a still image from the International Affective Picture System (IAPS; Lang, Bradley, \& Cuthbert, 2005). Between the blocks, a 30-s break was inserted. The stimuli consisted of one neutral (a spoon; IAPS \#7004), one positive (two bunnies; IAPS \#1750), one negative (a barking pit bull; IAPS \#1300), and one individually chosen trauma-related image. The order of the first three blocks was randomized, while all participants viewed the trauma-related image last.

Table 1 lists the IAPS pictures that were chosen as the individualized trauma-related image for the emotion provocation task. Following the trauma-related image, participants were asked to indicate the degree to which the image reminded them of their own traumatic experience on an 11point scale $(0=$ not at all, $10=$ very much $)$. Moreover, using three similar 11-point scales, they indicated how much the picture made them ruminate, how intense the emotions were if they had been reliving the traumatic experience, and whether they noticed an associated physical reaction (e.g., laughing, sweating, tachycardia).

\subsection{Physiological recordings and data reduction}

In line with published guidelines (Keil et al., 2014; Pivik et al., 1993), we measured EEG using an electrode cap with $\mathrm{Ag} / \mathrm{AgCl}$ electrodes positioned according to the International 10-20 system (American Electroencephalographic Society, 1994) at the locations FZ, F3, F4, F7, F8, FC3, FC4, CZ, C3, C4, T7, T8, PZ, P3, P4, P7, P8, PO3, PO4, PO7, PO8, and A2. By means of a BrainAmp EEG amplifier (Brain Products $\mathrm{GmbH}$, Germany), signals were sampled continuously at $250 \mathrm{~Hz}$, referenced online to the left mastoid (A1), band-pass filtered $(0.1-35 \mathrm{~Hz})$, and stored. An electrode at $\mathrm{AFz}$ served as signal ground. In addition, electrooculogram (EOG) electrodes were applied above and below the right eye and at the outer canthi of both eyes to measure vertical and horizontal eye movements. All electrode impedances were kept below $5 \mathrm{kOhm}$ with homologous scalp electrodes being within $1 \mathrm{kOhm}$ of each other.

\subsection{1 | Resting state frontal asymmetry}

In line with prior frontal asymmetry studies (for a review, see Allen et al., 2004; Meyer et al., 2014b; Quaedflieg et al., 2015), frontal asymmetry scores were determined according to the following data reduction procedure (BrainVision Analyzer 2.0 software; Brain Products, Germany). First, all EEG data were rereferenced offline to the average of A1 and A2 and band-pass filtered from 1 to $30 \mathrm{~Hz}$. Next, each 1-min block from the resting state measurement was divided in 2-s epochs (75\% overlap). Epochs were defined as artifact contaminated (e.g., by eye movement or muscle activity) and removed when vertical EOG or EEG activity exceeded thresholds of \pm 200 and $\pm 75 \mu \mathrm{V}$, respectively. On average, $70.5 \%$ $($ range $=12-100 ; \quad S D=21.2) \quad$ of eyes-open and $97.8 \%$ (range $=82-100 ; S D=3.8$ ) of eyes-closed epochs were artifact free. Then, we derived the power density for each retained epoch using fast Fourier transform (FFT) with a $100 \%$ Hanning window and calculated weighted averages across artifact-free epochs, separately for the eyes-open and eyes-closed conditions.

Following the procedure described in Quaedflieg et al. (2015), we determined frontal asymmetry scores based on each participant's individual alpha peak frequency (IAF). In contrast to relying on the standard alpha band (e.g., 8-13 $\mathrm{Hz}$ ), this approach takes the large interindividual variability in IAF into account and thereby increases the signal-to-noise ratio. IAF was defined as the dominant frequency rhythm between 5 and $15 \mathrm{~Hz}$ at the midline posterior electrode $(\mathrm{Pz})$ on the weighted average of the $4 \mathrm{~min}$ of resting eyes-closed data (see Doppelmayr, Klimesch, Pachinger, \& Ripper, 1998; Klimesch, 1999). The sample average IAF was 9.81 $\mathrm{Hz}$ (range: $7.3-12.2, S D=0.97$ ). The IAF bandwidth was defined as the $20 \%$ range above and below the IAF (i.e., on average from $7.85-11.77 \mathrm{~Hz}$ ), largely overlapping with the standard alpha band between 8 and $13 \mathrm{~Hz}$. Alpha asymmetry scores were calculated by subtracting the log-transformed alpha power density values at left from right frontal electrodes (i.e., $\ln [$ right $]-\ln [$ left] $)$, and then averaged across eyesopen and eyes-closed blocks.

The analyses concentrate on alpha power asymmetry in the widely used lateral frontal (F8, F7), midfrontal (F4, F3), and midline frontocentral leads (FC4, FC3). Each of these electrode pairs has been used in prior studies (cf. Gordon, Palmer, \& Cooper, 2010; Rabe, Beauducel et al., 2006; Wahbeh \& Oken, 2013) to determine frontal asymmetry in PTSD samples (for review, see Meyer, Smeets et al., 2015). Because we had identical hypotheses for each of these sites, we calculated a composite frontal asymmetry index (i.e., the mean of $\ln [\mathrm{F} 8], \ln [\mathrm{F} 4], \ln [\mathrm{FC} 4]-$ mean of $\ln [\mathrm{F} 7], \ln [\mathrm{F} 3], \ln [\mathrm{FC} 3])$, in order to reduce the number of statistical analyses and consequently the probability of Type I errors. Using this metric, we found high to excellent internal consistency across the eight resting state blocks $(\alpha=.89)$ and across the four emotion induction blocks $(\alpha=.86){ }^{2}$ To examine whether the asymmetry effects were specific to frontal sites, we calculated a similar asymmetry index for parietal sites (mean of $\ln [\mathrm{P} 8], \ln [\mathrm{P} 4]-$ mean of $\ln [\mathrm{P} 7]$, [P3]).

\footnotetext{
${ }^{2}$ For asymmetry scores that are derived from power density in the standard alpha band $(8-13 \mathrm{~Hz})$, we found almost identical internal consistencies (resting: $\alpha=.89$, induction: $\alpha=.88$ ). Moreover, we repeated the main correlation analyses reported in Table 4 with these scores, finding basically the same results (see online supporting information Table S2).
} 


\subsubsection{Frontal activation asymmetry during emotion provocation}

In the same manner as for the resting state measurements, average power densities were calculated for the four 2-min blocks of the emotion provocation task. On average, for the 2-min blocks (237 epochs) with neutral, positive, negative, and reminder pictures, we retained respectively $63.6 \%$ $(S D=27.6), 60.3 \%(S D=28.2), 64.2 \%(S D=27.5)$, and $59.0 \%(S D=27.5)$ of the epochs after artifact rejection. These percentages did not vary as a function of group, or Group $\times$ Phase, all $p s>$.21. For the purpose of correlational analyses, we calculated activation asymmetry scores (similar to Rabe, Beauducel et al., 2006) by subtracting each individual's resting state frontal asymmetry from the asymmetry scores during each of the emotion induction blocks (for details on this decision, see Results).

\subsection{Self-report scales to control for individual differences}

\subsection{1 | Common symptoms of psychopathology}

To check for the specificity of potential findings to trauma-related symptoms, we used the Brief Symptom Inventory (BSI; Boulet \& Boss, 1991) as an overall measure of psychopathology. It consists of 53 items that describe a variety of psychological complaints and require respondents to indicate the degree of distress caused by them on 5-point scales ranging from 0 (not at all) to 4 (extremely). For our analyses, we used the mean score across all items $(\alpha=.98)$. Moreover, the trait subscale of the State-Trait Anxiety Inventory (STAI; Spielberger, 1983) and the revised Beck Depression Inventory (BDI-II; Beck, Steer, \& Brown, 1996) were employed to measure stable individual differences in anxiety and depression levels, respectively. The STAI consists of two 20-item subscales that tap into state and trait anxiety, using 4-point scales (range: 1-4). The BDI-II consists of 21 items that screen for depression and are rated on 4-point scales (range 0-3). The sum scores of the two scales were used to quantify trait anxiety $(\alpha=.96)$ and depression $(\alpha=.92)$, respectively.

\subsection{2 | Symptom validity}

To assess symptom overreporting tendencies, the Structured Inventory of Malingered Symptomatology (SIMS; Merckelbach \& Smith, 2003; Smith \& Burger, 1997), consisting of 75 true-false statements, was used. The statements represent rare or atypical symptoms of different clinical conditions, namely, low intelligence, affective disorders, neurological impairment, psychosis, and amnesia. One low intelligence item was removed from the scoring because the correct answer changed in the course of the study ("Beatrix is the
Queen of the Netherlands"). Most commonly, the SIMS is used as a tool to detect malingering by means of cut-off scores. When used as a dimensional measure, studies have shown that nonextreme scores are positively related to genuine levels of psychopathology (e.g., Dandachi-FitzGerald, Ponds, Peters, \& Merckelbach, 2011). Therefore, next to using the total SIMS score $(\alpha=.82)$, we also used the low intelligence subscale (e.g., "I am unable to count from 20 to 1 without making a mistake") and the psychosis subscale (e.g., "When I hear voices, it feels as if my teeth were leaving my mouth"), both of which have no conceptual overlap with the variables of interest in our study and have been shown to discriminate well between honest and feigning responders (Dandachi-FitzGerald et al., 2011). Both subscales had very low internal consistencies (psychosis: $\alpha=.11$; low intelligence $\alpha=.07$ ), which is likely due to the presence of zero-variance items (items that none of the participants endorsed), and which is in line with the view that these scales capture item-unspecific response tendencies rather than an underlying psychological construct.

\subsection{3 | Handedness and current mood}

We included the Edinburgh Handedness Inventory (EHI; Oldfield, 1971) to determine motor lateralization (i.e., handedness). Finally, we included a measure of current mood prior to the resting state measurement, using the State version of the Positive and Negative Affect Schedule (PANAS; Watson, Clark, \& Tellegen, 1988). This scale consists of two 10item subscales with adjectives, respectively describing positive affect (e.g., interested; $\alpha=.87$ ) and negative affect (e.g., distressed; $\alpha=.94$ ), and requiring responses on 5-point Likert scales $(1=$ very slightly or not at all; $5=$ extremely $)$. Items on each scale are summed, and higher scores indicate higher current positive and negative affect, respectively.

\section{7 | Procedure}

\subsection{1 | Session 1}

Trauma-exposed participants were invited to two individual lab sessions, separated by an interval of 8 days. The first session was scheduled in the afternoon in order to reduce possible diurnal fluctuations in frontal asymmetry (Velo, Stewart, Hasler, Towers, \& Allen, 2012). Participants were instructed beforehand to refrain from drugs and alcohol for $24 \mathrm{~h}$, and from heavy physical activities, smoking, or drinking coffee immediately prior to participation. Upon arrival, they were seated in an electrically shielded and soundproof cabin and were given a word learning task (data not included here). Next, the EOG and EEG electrodes were prepared, while participants filled out questionnaires (including biographical data, 
EHI) on the computer. Following electrode preparation, the participants were left alone in the cabin and were given the trauma screening form and a form asking about typical waking hours (in order to program the diary app). When they had completed them, the experimenter checked the responses and briefly discussed the trauma screening form with the participant in order to select a trauma-relevant picture for the reminder task. Then, participants performed a recall test from the word learning task. Participants were later shown the raw EEG and EOG signals to demonstrate common sources of artifacts (e.g., body and eye movements), filled out the PANAS, and underwent the resting state measurement. Afterward, they performed an unrelated, nonemotional visual search task lasting approximately $30 \mathrm{~min}$, followed by the emotion provocation task. Finally, they were given the smartphone and the diary that they were to complete for 7 days (starting the day after Session 1) and received extensive written and verbal instruction on their use. Moreover, they were given a demonstration with the smartphone of how to report an intrusion and fill out the affect grids.

\subsection{2 $\quad$ Session 2}

One week later, participants returned the smartphone and the diary, and the experimenter checked the diary for correct use and readability together with the participant. This was followed by administration of a questionnaire battery on the computer that included the PCL, PSS-SR, RIQ, BSI, STAI, BDI-II, and the SIMS. Finally, the participants were fully debriefed and received $75 €$ as a compensation for their participation.

\subsection{3 | Healthy control group}

The healthy controls were invited to a single laboratory session. The procedure was similar to the first session of the trauma-exposed group, except that these participants were given the same questionnaire battery that trauma-exposed participants completed in Session 2 immediately following the emotion induction task. No ambulatory diary measures were taken in this group. These participants received $30 €$ to compensate them for participating.

\section{8 | Statistical analyses}

Single extreme values in resting and emotion provocation EEG asymmetries were replaced such that their deviance from the sample mean equated 2.5 times the sample $S D$ (i.e., Winsorizing; Rivest, 1994). We used analysis of variance (ANOVA) and $t$ tests to test differences between the diagnostic groups in our sample. Our main analyses address the relationship between frontal asymmetry and PTSD symptoms using Pearson product-moment correlations and partial correlation analyses. Furthermore, we used repeated measures analysis of covariance (ANCOVA) to test whether PTSD symptoms modulated frontal asymmetry scores and vice versa. When sphericity assumptions for ANCOVA were violated, Greenhouse-Geisser corrected $p$ values are reported along with the respective epsilon and uncorrected degrees of freedom. Alpha was set at .05 (two-tailed). Where applicable, follow-up pairwise comparisons were performed, and in those cases we consistently report Bonferroni-corrected $p$ values. In the correlation analyses, we corrected alpha for multiple testing. For an optimal balance between the risk of Type I and Type II errors, we used the Bonferroni tool from Simple Interactive Statistical Analysis (SISA; www.quantitativeskills.com/sisa/calculations/bonfer.htm), which takes the average correlation among dependent variables into account.

\section{3 | RESULTS}

\section{1 | Sample characteristics}

\subsection{1 | Retrospective symptom assessment}

Symptoms of PTSD, anxiety, depression, and overall psychopathology are summarized in Table 2. There were no group differences in age, gender ratio, handedness, and time since the index trauma among trauma-exposed participants. While there were no group differences in state positive affect in Session 1, we did find group differences in state negative affect. Pairwise comparisons showed that participants diagnosed with PTSD had higher negative affect levels prior to the EEG resting state measurement than the other two groups, $p s \leq .01$, whereas the no-PTSD group did not differ from healthy controls, $p>.99$.

The analyses further confirm the allocation of participants into three groups, with higher PCL total scores in participants with PTSD compared with trauma-exposed participants without PTSD (pairwise $p<.001$ ), who had higher scores than healthy controls, $p=.022$. Similarly, pairwise comparisons indicated that the PTSD group scored higher on PSS-SR reexperiencing and avoidance symptoms than the two other groups, $p s<.001$, while there was no difference between trauma-exposed participants without PTSD and healthy controls, $p s>.26$. For PSS-SR hyperarousal symptoms, pairwise comparisons indicate significant differences between all groups, $p$ s $<.01$, with highest scores in the PTSD group and lowest in the healthy controls. For the STAI-T, BDI-II, and BSI scores, but also for the SIMS total scores, significantly higher scores were found in the PTSD group compared to the other two groups, all $p \mathrm{~s}<.01$, while there were no differences between trauma-exposed participants without PTSD and healthy controls, all $p s>.11$. 
TABLE 3 Intrusion diary responses

\begin{tabular}{|c|c|c|c|}
\hline Method & & PTSD $(n=23)$ & No-PTSD $(n=15)$ \\
\hline \multirow[t]{3}{*}{ Diary intrusions } & Total & $6.22(5.14)$ & $2.40(3.04)$ \\
\hline & Image-based & $4.13(4.17)$ & $1.33(1.40)$ \\
\hline & Thought-based & $4.87(4.12)$ & $2.07(3.08)$ \\
\hline \multirow[t]{3}{*}{ Affective responses } & Distress & $70.1(15.7)$ & $39.1(36.2)$ \\
\hline & Intensity & $65.2(20.4)$ & $19.6(35.9)$ \\
\hline & Physical reaction & $51.1(24.1)$ & $27.4(35.4)$ \\
\hline \multirow[t]{2}{*}{ Diurnal characteristics } & Sleep quality & $60.6(14.1)$ & $71.3(18.2)$ \\
\hline & Diurnal stress level & $47.7(13.0)$ & $33.8(16.1)$ \\
\hline
\end{tabular}

Note. Standard deviations of the mean appear in parentheses.

Importantly, however, no group differences emerged for the SIMS psychosis and low intelligence subscales.

Finally, significant group differences also emerged on the RIQ rumination subscale, $F(2,49)=7.59, p=.001$, $\eta_{\mathrm{p}}^{2}=.24$, and on the RIQ negative appraisal subscale, $F=19.33, p<.001, \eta_{\mathrm{p}}^{2}=.44$. PTSD patients had higher rumination scores $(M=19.7, S D=4.2)$ than controls $(M=13.8, S D=3.5), p=.001$, while the no-PTSD group $(M=16.7, S D=5.8)$ did not differ significantly from the other groups, $p s>.15$. Furthermore, participants with PTSD scored higher on negative appraisal of intrusions $(M=18.6$, $S D=3.4)$ compared to the no-PTSD group $(M=13.5$, $S D=3.3)$ and to controls $(M=13.0, S D=2.0), p s<.001$, with no difference between no-PTSD and control participants, $p>.99$.

\subsection{2 | Ambulatory assessment}

Table 3 summarizes the intrusions recorded in the diary by the trauma-exposed participants, separately for those diagnosed with and without PTSD. As could be expected, participants with PTSD reported more intrusions than traumaexposed participants without PTSD, irrespective of whether the intrusions had an image or a thought component, all $t \mathrm{~s}$ $(d f=36)>.2 .94, p \mathrm{~s}<.01$. The former group also reported higher levels of distress $(t=3.14, p=.006)$, emotional intensity $(t=2.52, p=.020)$, and physical reactions to the intrusions $(t=2.27, p=.033)$. Moreover, participants with PTSD tended to report lower mean sleep quality $(t=-2.03$, $p=.050)$ and higher levels of diurnal stress unrelated to the intrusions $(t=2.93, p=.006)$.

In all trauma-exposed participants, the (log-transformed) frequency of intrusions in the diary corresponded with the number of intrusions that were recorded in parallel via the smartphone, $r(38)=.54, p<.001$. In total, 27 of the 38 trauma-exposed participants (18 diagnosed with PTSD) reported at least one intrusion using the smartphone and filled out the corresponding affect grids. Among this sub- group, PTSD symptoms tended to correlate with lower weekly valence scores (PCL score $r=-.36, p=.064$; PSSSR total $r=-.39, p=.047$ ), but not with arousal scores (largest $r=-.26, p=19$ ). Valence and arousal scores did not differ significantly between those diagnosed with and without PTSD, all $t \mathrm{~s}(25)<0.89, p \mathrm{~s}>.38$.

In order to assess possible interactions of PTSD symptoms with the time course of valence scores, we performed a repeated measures ANCOVA for all trauma-exposed participants (irrespective of their diagnostic status) with time (3: immediate, $+15 \mathrm{~min},+30 \mathrm{~min}$ ) as within-subject factor and mean weekly valence level and PCL total score as covariates. This revealed that the factor time interacted both with PCL scores, $F(2,48)=4.56, \epsilon=.64, p=.033, \eta_{\mathrm{p}}^{2}=.16$, and with weekly valence levels, $F(2,48)=4.17, \epsilon=.64, p<.041$, $\eta_{\mathrm{p}}^{2}=.15$. A similar interaction of time with PTSD symptoms emerged when PSS-SR scores were entered instead of PCL scores, $F(2,48)=5.18, \epsilon=.66, p=.022, \eta_{p}^{2}=.18$. Moreover, it also emerged at trend level in a repeated measures ANOVA, where we entered diagnostic group instead of continuous PTSD symptoms (2: PTSD, no-PTSD) as betweensubjects factor, $F(2,50)=2.95, \epsilon=.64, p<.086, \eta_{\mathrm{p}}^{2}=.11$. The nature of this interaction can be seen in Figure 1. Valence reactivity scores differed between the diagnostic groups only immediately following an intrusion, $t(25)=-$ $2.3, p=.030$, but not 15 or 30 min later, all $p s>.12$. Meanwhile, similar ANCOVAs for arousal levels did not reveal any significant main or interaction effects involving time (all $p s>.09$ ) or PTSD symptoms (all $p s>.37$ ). Only mean weekly arousal levels tended to be associated with arousal levels following an intrusion, $F(1,24)=3.69, p=.067$, $\eta_{\mathrm{p}}^{2}=.13$.

\subsection{3 | Emotion provocation task}

Subjective responses to the trauma-related picture during the emotion provocation task are summarized in Figure 2. ANOVAs comparing the three groups revealed significant 
9

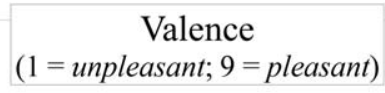

5

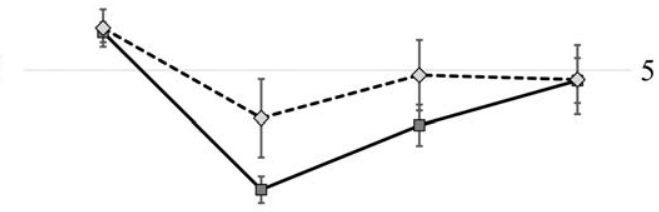

9

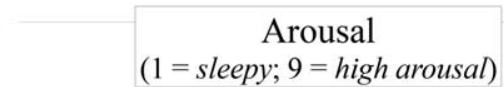

$(1=$ sleepy; $9=$ high arousal $)$

1

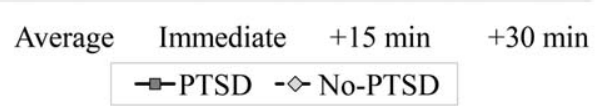

1

Average Immediate $+15 \mathrm{~min} \quad+30 \mathrm{~min}$

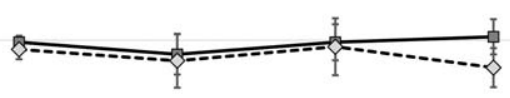

F IG U RE 1 Valence (left panel) and arousal (right panel) levels during 1 week (average) and at three time points following intrusive memories. Error bars indicate standard errors

group differences on all five included items, $F \mathrm{~s}(2,51)>7.47$, $p \mathrm{~s} \leq .001, \eta_{\mathrm{p}}^{2} \mathrm{~s}>.22$. Importantly, pairwise comparisons revealed that trauma-exposed individuals with and without PTSD similarly indicated that the picture reminded them of their own traumatic experience, $p=.33$, and both groups scored significantly higher than the trauma-free controls, both $p \mathrm{~s}<.001$. Furthermore, both trauma-exposed groups tended to score higher on all other items compared to the trauma-free control group, all $p \mathrm{~s} \leq .05$, while the scores did not differ between participants with and without PTSD, all $p s>.28$.

\section{2 | Frontal asymmetry}

\subsection{1 | Group differences}

Mean frontal asymmetry scores per group are displayed in Figure 3. At first, we ran a 5 (Phase: resting, neutral, positive, negative, trauma-related) $\times 3$ (Group: PTSD, no-PTSD, controls) repeated measures ANOVA on frontal asymmetry scores. This revealed a significant Phase $\times$ Group interaction, $F$ $(8,204)=2.62, p=.010, \eta_{p}^{2}=.09$, as well as a group main effect, $F(2,51)=6.00, p=.005, \eta_{\mathrm{p}}^{2}=.19$, in the absence of a main effect for phase, $F(4,204)=1.20, p=.31, \eta_{\mathrm{p}}^{2}=.02$. To explore the nature of the Phase $\times$ Group interaction, we ran follow-up ANOVAs per phase, yielding a significant group effect during the resting state phase, $F(2,51)=10.91$, $p<.001, \eta_{\mathrm{p}}^{2}=.30$. Here, frontal asymmetry scores did not differ between the two trauma-exposed groups, $p=.29$, but, unexpectedly, both of these groups had more left-sided activity compared to the healthy control group ( $p \mathrm{~s}<.004)$.

In contrast, different patterns emerged in the emotion provocation task. We found significant group effects for neutral and negative picture viewing, $F(2,51)=3.84, p=.028$, $\eta_{\mathrm{p}}^{2}=.13$, and $F=8.46, p=.001, \eta_{\mathrm{p}}^{2}=.25$, respectively. In these two conditions, trauma-exposed participants without PTSD (i.e., relatively more resilient individuals) had higher left-sided activity than participants with PTSD, $p s<.024$, and, in the negative picture condition, they also had higher scores than control participants, $p=.027$. Meanwhile, there were no group differences in the positive picture condition, $F=1.46, p=.24, \eta_{\mathrm{p}}^{2}=.05$, and, against our expectations, neither were there in the trauma-related picture condition, $F=2.26, p=.11, \eta_{\mathrm{p}}^{2}=.08$.

For comparison, we repeated the 5 (Phase) $\times 3$ (Group) repeated measures ANOVA for parietal alpha asymmetry scores. This revealed a similar Phase $\times$ Group interaction, $F$ $(8,204)=2.83, \quad \epsilon=.71, \quad p=.014, \quad \eta_{\mathrm{p}}^{2}=.10 . \quad$ Follow-up ANOVAs indicated that there only was a group difference in the resting state, $F(2,51)=3.39, p=.041, \eta_{\mathrm{p}}^{2}=.12$, but not in any of the other phases, all $p \mathrm{~s}>.54$. In the resting state,

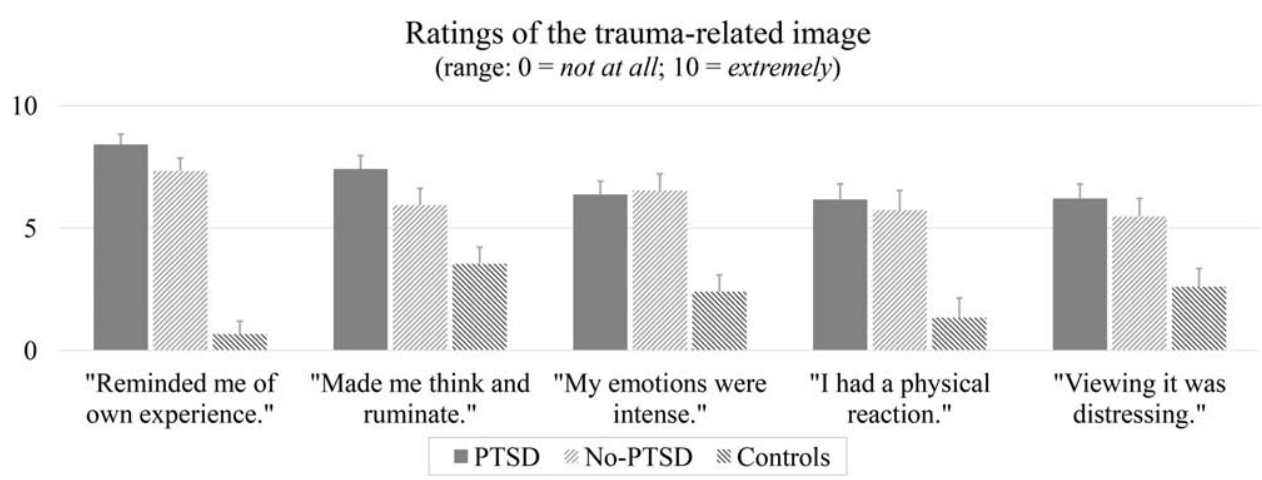

FIGURE 2 Subjective responses to the trauma-related image in the emotion provocation task. Error bars indicate standard errors 
Frontal asymmetry scores per group and condition

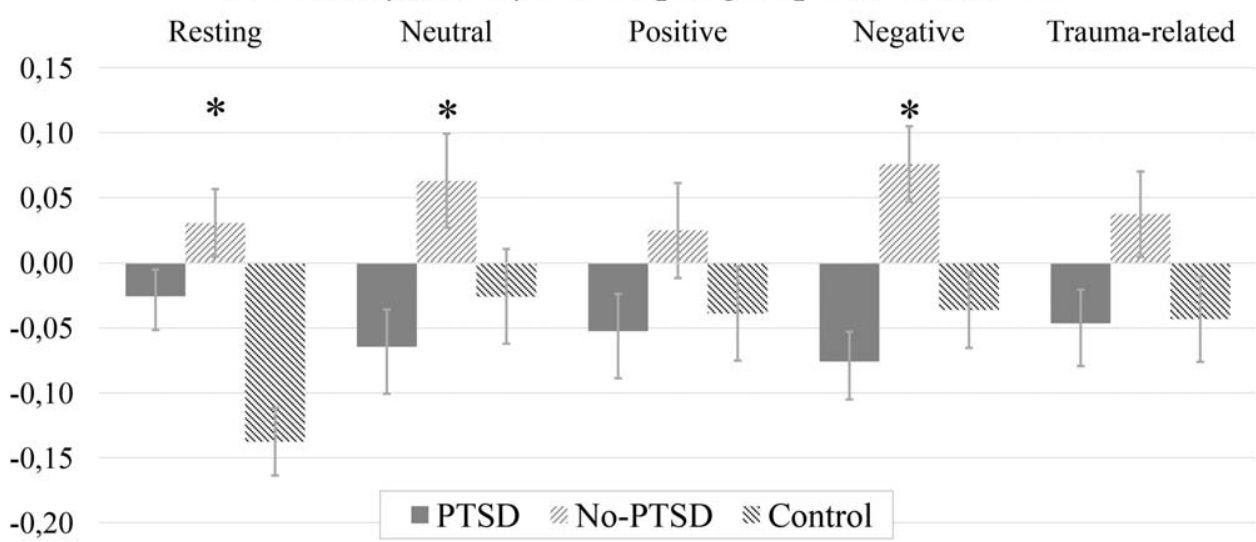

FIG URE 3 Frontal asymmetry scores per group and condition. Asterisks indicate a significant simple effect of group. Error bars indicate standard errors

control participants had lower parietal asymmetry scores than the PTSD group, while there were no differences among the two trauma-exposed groups. Thus, the deviant resting frontal asymmetry scores of the control group were also reflected in parietal alpha asymmetry, whereas this was not the case during the emotion induction phases. Importantly, the two trauma-exposed groups did not differ in parietal asymmetry, irrespective of measurement phase.

\subsubsection{Correlation analyses in trauma- exposed participants}

In line with the PTSD study by Rabe, Beauducel et al. (2006), we assessed the correlations between symptoms and frontal asymmetry scores based on the resting state measurement, as well as using baseline-corrected activation asymmetry scores during the emotion induction blocks. Because

TABLE 4 Correlations between frontal asymmetry scores and PTSD-related outcomes

\begin{tabular}{|c|c|c|c|c|c|}
\hline Measure & Resting & Neutral & Positive & Negative & Trauma \\
\hline PCL score & -.04 & -.15 & -.15 & $-.47 *$ & -.24 \\
\hline Reexperiencing & .12 & $-.42 *$ & -.29 & $-.54 * *$ & $-.39 \dagger$ \\
\hline Avoidance & -.14 & -.14 & -.11 & $-.42 *$ & -.11 \\
\hline RIQ-Negative appraisal & .05 & -.23 & -.09 & $-.57 * *$ & -.33 \\
\hline \multicolumn{6}{|c|}{ Correlations with diary outcomes $(n=38)$} \\
\hline Intrusions total & .08 & -.33 & -.14 & $-.37 \dagger$ & -.32 \\
\hline Image intrusions & .07 & -.31 & -.13 & -.32 & -.22 \\
\hline \multicolumn{6}{|c|}{ Correlations with subjective responses to trauma-related image $(n=39)$} \\
\hline Rumination & -.03 & -.23 & .02 & -.26 & $-.36 \dagger$ \\
\hline Emotional intensity & $.41 *$ & -.32 & -.22 & -.33 & $-.50 * *$ \\
\hline Physical reaction & .23 & -.11 & .02 & -.24 & $-.40 *$ \\
\hline Distress & .28 & -.13 & .05 & -.19 & -.29 \\
\hline
\end{tabular}

Note. Alpha was adjusted for multiple testing with 17 dependent variables and for the average correlation among the dependent variables $(r=.49)$. PCL $=$ PTSD Checklist (Civilian version); PSS-SR = PTSD Symptom Scale-Self-Report; RIQ = Response to Intrusions Questionnaire.

$\dagger p<.024(\alpha=0.10) .{ }^{*} p<.012(\alpha=0.05) .{ }^{* *} p<.002(\alpha=0.01)$. 
TABLE 5 Correlations with anxiety, depression, psychopathology, and current affect levels

\begin{tabular}{|c|c|c|c|c|c|}
\hline Measure & Resting & Neutral & Positive & Negative & Trauma \\
\hline STAI-T & -.19 & -.09 & -.17 & $-.47 * *$ & $-.33 \dagger$ \\
\hline BSI & .05 & -.13 & -.28 & $-.53 * *$ & -.30 \\
\hline \multicolumn{6}{|c|}{ Correlations with state negative affect prior to the resting state measurement $(n=39)$} \\
\hline
\end{tabular}

frontal asymmetry scores differed significantly during neutral picture viewing between PTSD and no-PTSD participants, we used resting-state frontal asymmetry scores as the baseline condition. Thus, we subtracted resting state frontal asymmetry scores from the asymmetries during neutral, positive, negative, and trauma-related picture viewing. The derived scores reflect activation asymmetry, whereby higher scores indicate stronger left-sided frontal activation (i.e., right-sided increase in alpha power) in response to picture viewing. The direct linear associations between these scores and PTSD symptom are summarized in Table 4. As can be seen, relatively more left-sided activation in the negative condition correlated with lower scores on all retrospective PTSD scales (except for intrusion-related rumination). In the trauma-related condition, trends indicate a more specific association with reexperiencing symptoms, and left-sided activation was significantly associated with lower emotional intensity of intrusions and of the trauma-related image.

For comparison, we repeated the correlation analyses for parietal asymmetry scores (see online supporting information Table S3). Resting parietal asymmetry was not significantly related to any of the outcomes, and there were no associations with retrospective PTSD symptoms or diary outcomes. However, correlations emerged between more left-sided parietal activation during the emotion provocation task and rumination and negative appraisal of intrusions, as well as with subjective rumination and emotional intensity while viewing the trauma-related picture. These findings suggest that the associations with PTSD symptoms and diary outcomes in Table 4 are specific to asymmetric activation at frontal sites, while those with ruminative responses to intrusions and emotional intensity of the trauma image are not.

\subsection{3 | Valence and arousal responses to intrusions}

To explore whether frontal asymmetry scores were associated with levels or time course of valence or arousal following an intrusion, we performed repeated measures ANCOVAs with time (3: immediate, $+15 \mathrm{~min},+30 \mathrm{~min}$ ) as within-subject factor, baseline valence or arousal levels as a covariate, and frontal asymmetry scores as a covariate, focusing on potential main or interaction effects involving frontal asymmetry. For the valence analyses, there were no interaction effects with resting or activation asymmetry scores from the emotion provocation task, all $F_{\mathrm{s}}(2,48)<0.70, p \mathrm{~s}>.45, \eta_{\mathrm{p}}^{2} \mathrm{~s}<.03$, and no main effects, all $F \mathrm{~s}(1,24)<1.93, p \mathrm{~s}>.18, \eta_{\mathrm{p}}^{2} \mathrm{~s}<.07$.

Also for arousal, there were no interaction effects, all $F$ s $(2,48)<2.47, p s>.11, \eta_{\mathrm{p}}^{2} \mathrm{~s}<.09$, and no main effects, all $F \mathrm{~s}$ $(1,24)<0.35, p s>.56, \eta_{p}^{2} s<.02$, with the exception of activation asymmetry during neutral picture viewing, which interacted with time, $F(2,48)=11.50, p<.001, \eta_{\mathrm{p}}^{2}=.32$. Within-subject contrasts indicated that the interaction was linear, $F(1,24)=16.58, p<.001, \eta_{p}^{2}=.41$, which was further supported by the finding that more left-sided activation asymmetry during neutral picture viewing correlated with higher arousal levels immediately following an intrusion, $r$ $(27)=.40, p=.040$, while there was no association after 15 $\min (r=-.01, p=.95)$, and a nonsignificant negative correlation after $30 \mathrm{~min}(r=-.23, p=.24)$. Thus, overall, resting frontal asymmetry appeared to have no link with affect levels following intrusive memories, while we found only limited and suggestive evidence that left-sided activation during the emotion provocation task is associated with the postintrusion time course of arousal levels.

\subsubsection{Uniqueness of the effects to PTSD}

In order to test whether the associations between resting and activation frontal asymmetries with PTSD symptoms are shared with symptoms of anxiety, depression, and overall psychopathology, we ran correlation analyses with STAI-T, BDI-II, and BSI scores. As can be seen in Table 5, higher left-sided frontal activation in the negative picture condition again predicted lower levels of symptoms, while the effects 
TABLE 6 Partial correlations ( $\mathrm{df}=33)$ with PTSD-related outcomes, corrected for trait anxiety (STAI-T), depression (BDI-II), and overall psychopathology (BSI)

\begin{tabular}{|c|c|c|c|c|c|}
\hline Measure & Resting & Neutral & Positive & Negative & Trauma \\
\hline PCL score & -.13 & -.06 & .19 & .06 & .10 \\
\hline Reexperiencing & .14 & $-.47 *$ & -.26 & -.26 & -.30 \\
\hline Avoidance & -.27 & -.05 & .03 & -.06 & .13 \\
\hline RIQ-Negative appraisal & .15 & -.23 & .01 & -.31 & -.21 \\
\hline \multicolumn{6}{|c|}{ Partial correlations with diary outcomes } \\
\hline Intrusions total & .10 & -.31 & -.05 & -.10 & -.21 \\
\hline Image intrusions & .08 & -.28 & -.05 & -.08 & -.10 \\
\hline \multicolumn{6}{|c|}{ Partial correlations with subjective responses to trauma-related image } \\
\hline Rumination & -.10 & -.23 & .14 & -.12 & -.33 \\
\hline Emotional intensity & .37 & -.34 & -.14 & -.26 & $-.53 * *$ \\
\hline Physical reaction & .21 & -.16 & .08 & -.16 & $-.41 \dagger$ \\
\hline Distress & .30 & -.19 & -.02 & -.11 & -.34 \\
\hline
\end{tabular}

Note. Alpha was adjusted for multiple testing with 17 dependent variables and for the average correlation among the dependent variables $(r=.49)$. PCL $=$ PTSD Checklist (Civilian version); PSS-SR $=$ PTSD Symptom Scale-Self-Report; RIQ = Response to Intrusions Questionnaire

$\dagger p<.024(\alpha=0.10) .{ }^{*} p<.012(\alpha=0.05) . * * p<.002(\alpha=0.01)$.

in the trauma-related condition were similar in direction but not statistically significant. Meanwhile, negative affect levels prior to the EEG measurement were associated with lower activation asymmetry scores throughout the emotion induction task, and especially so in the negative picture condition.

Based on these findings, it is possible that the associations described in Table 4 do not reflect effects that are unique to PTSD, but in part reflect effects that are shared with anxiety, depression, and other common symptoms of psychopathology. To address this possibility, we performed partial correlation analyses, correcting for STAI-T, BDI-II, and BSI scores (including only participants with complete data on all questionnaires). The results are summarized in Table 6. As can be seen, several partial correlations were still statistically significant and align with the zero-order correlations. The effects for retrospective measures were reduced in size and largely nonsignificant. In the intrusion diary, activation asymmetries in response to the neutral and the traumarelated picture remained significant predictors of the emotional intensity during intrusions. Consistent with this finding, activation asymmetry scores in the trauma-related condition also predicted lower emotional intensity ratings directly after viewing the trauma-related picture.

\subsection{5 | Symptom validity}

Finally, we tested whether symptom overreporting tendencies might have affected the results. Therefore, we applied a conservative cutoff score for the SIMS and defined participants with a score higher than 16 as potentially displaying overreporting tendencies (Merckelbach \& Smith, 2003). Based on this criterion, we excluded five participants, and we also removed a sixth participant for whom no SIMS data were available. We then repeated the main correlation analyses that are reported in Table 4 in the remaining 32 participants. The results can be inspected in supporting information Table S1. Strikingly, despite the considerable reduction in statistical power, these analyses show that virtually all effects of activation asymmetry during negative and trauma-related picture viewing increase in size. Therefore, in this subsample, overall PTSD symptoms are highly correlated with activation asymmetry during negative picture viewing (PCL: $r=-.55$; PSS-SR: $r=-.60 ; p \mathrm{~s} \leq .001)$, and also in the trauma-related picture condition (PCL: $r=-.43$; PSS-SR: $r=-.41 ; p \mathrm{~s} \leq .019)$. Moreover, left-sided frontal activation in the trauma-related condition now correlated significantly with fewer reexperiencing symptoms $(r=-.47)$ and intrusive memories $\quad(r=-.42)$. Thus, symptom overreporting 
tendencies in some participants are highly unlikely to be driving the effects of frontal asymmetry reported in this paper, and might even have dampened true associations.

\section{4 | DISCUSSION}

The present study addressed frontal EEG asymmetry as a potential marker of PTSD symptoms in trauma victims. Replicating prior EEG studies in traumatized samples (for review, see Meyer, Smeets et al., 2015), we explored the association between PTSD symptoms and frontal asymmetry at rest and in response to emotional provocation, including a condition where participants viewed a trauma-related picture. Our study extends prior findings by supplementing retrospective measures with ambulatory symptom assessment and a laboratory provocation, providing a closer look at various PTSD symptoms in daily life (Chun, 2016). A particular interest was in reexperiencing symptoms, including intrusive trauma memories and their ensuing cognitive-emotional reactions. Moreover, we included measures of general psychopathology and symptom exaggeration tendencies to assess whether potential effects would be specific to PTSD and robust against reporting bias.

The main findings can be summarized as follows. First, our results replicate and extend prior findings (Rabe et al., 2008; Rabe, Zöllner, Maercker, \& Karl, 2006) and support the view that provocation-induced frontal activation asymmetry is more closely linked with PTSD symptoms than resting state asymmetry, which was unrelated to all retrospective symptoms. Second, higher left-sided frontal activation in response to a negative picture most consistently predicted fewer PTSD symptoms, both assessed in the intrusion diary, the emotion provocation task, and retrospectively. It was similarly associated with lower levels of depression, anxiety, and general symptoms of psychopathology, and partial correlation analyses correcting for these factors revealed that these effects are likely to be shared between PTSD and other mental disorders. Third, left-sided frontal activation in response to an individually chosen trauma-related picture did not show similarly consistent associations with retrospective PTSD symptoms, but was more specifically associated with fewer reexperiencing symptoms. Notably, it predicted less intense responses to intrusions and in response to viewing the trauma-related picture, even when corrected for other symptoms of psychopathology and for symptom overreporting tendencies. However, valence and arousal levels immediately following intrusions appeared to be unrelated to this marker. Fourth, and more surprisingly, we also found that activation asymmetry in response to a neutral picture had similar relationships with various symptoms, albeit less consistently across outcome measures. Finally, group analyses that compared trauma survivors with and without a diagnosis of PTSD with a healthy, trauma-free control group revealed that trauma victims without PTSD (i.e., relatively more resilient individuals) displayed more left-sided frontal activation in response to the negative picture than victims with PTSD and controls. In line with the correlation analyses, a similar pattern emerged for the neutral picture condition, but, unexpectedly, not for the trauma-related picture condition. Meanwhile, and contrary to our expectation, controls had lower left-sided activity at rest than the trauma-exposed groups.

In general, our results largely replicate Rabe, Beauducel et al. (2006), who found that right-sided frontal activation in response to a trauma picture was associated with PTSD symptoms, depression, anxiety, and negative affect levels, in trauma victims who had experienced a motor vehicle accident. Our results also align well with findings of increased right-sided frontal activation during anxiety provocation in individuals with social phobia (Davidson, Marshall, Tomarken, \& Henriques, 2000) and panic disorder (Wiedemann et al., 1999). We extend these prior findings by showing that similar associations exist with PTSD reexperiencing symptoms in daily life, including the number and intensity of intrusive memories, in individuals with mixed traumatic experiences. Moreover, by including the SIMS as a symptom validity scale, we were able to demonstrate that the associations reported here are not carried by individuals with a tendency toward symptom overreporting. Taken together, the present findings suggest that frontal activation asymmetry during emotional provocation can serve as a biomarker that is informative about PTSD symptom levels, and also specifically linked with the intensity of reexperiencing symptoms.

Unlike Rabe, Beauducel et al. (2006), we found frontal activation asymmetry to correlate with PTSD symptoms also in the negative picture condition, and to some degree even in the neutral picture condition. Although we used the same picture stimuli as Rabe and colleagues for the neutral, positive, and negative emotion conditions, procedural differences with their study may account for this disparity. That is, these authors included only victims of motor vehicle accidents, and therefore used the same trauma-related picture for all participants. In contrast, we selected the trauma-related picture individually using each participant's description of their index traumatic experience. Since participants were fully aware of the type of stimuli that would be presented, this may have led to stronger anticipatory fear, knowing that they would be reminded of their personal traumatic experience. Arguably, this anticipation effect might have exerted its influence most strongly in the neutral picture condition. In other words, even though participants viewed a neutral picture, this condition appears unlikely to have induced an affectively neutral state. This 
interpretation also aligns with the finding that the PTSD group had lower frontal asymmetry scores than the noPTSD group during neutral picture viewing, while there were no similar group or correlation effects for the resting state or the positive picture condition.

It is also noteworthy that frontal activation asymmetry in the negative picture condition was strongly associated with almost all measures of PTSD symptoms, except for the acute rumination, physical reactions, and distress caused by viewing the trauma-related image. Interestingly, analyses further revealed that a large part of these associations are shared with depression, anxiety, and general psychopathology, suggesting that they do not reflect effects that are unique to PTSD. In contrast, activation asymmetry during the traumarelated image tended to be associated more specifically with reexperiencing symptoms in daily life and in response to viewing the image, and these effects tended to remain significant when corrected for other symptoms of psychopathology. Therefore, our data suggest that frontal activation asymmetry during emotion provocation can inform about a wide range of psychopathological symptoms, whereas it can also more specifically predict reexperiencing symptoms when measured while participants view an idiosyncratic, trauma-related picture.

From a theoretical point of view, it is noteworthy that provocation-induced frontal asymmetries in the negative and the trauma-related conditions were associated with hyperarousal-related PTSD symptoms, including the emotional intensity associated with traumatic memories. Some of these effects were also evident in parietal alpha asymmetries. Interestingly, the valence-arousal model of hemispheric asymmetry (Heller et al., 1997; Nitschke et al., 1999) proposes that anxious arousal is characterized by right parietal activation, whereas frontal asymmetry would more specifically reflect anxious apprehension. Accordingly, right-sided parietal activation patterns might play a role in the associations between frontal asymmetry and hyperarousal symptoms. However, this view is challenged by the finding that parietal asymmetries were only linked with the emotional intensity in response to viewing the trauma-related picture, and not with the emotional intensity of intrusive memories. Furthermore, parietal asymmetries were associated with ruminative responses and with negative appraisal of intrusions. Taken together, our findings provide only partial support for the valence-arousal model, which warrants further critical investigation of the regional specificity of asymmetry effects.

Another finding that may inspire future research is that trauma-exposed participants with stronger left-sided frontal activity at rest displayed more emotionally intense traumatic memories, and that left-sided activation asymmetry during neutral picture viewing tended to correlate with higher arousal levels immediately following an intrusion.
These results appear to contravene the overall pattern in our results (i.e., left-sided frontal activity predicting fewer PTSD symptoms), yet they align with the finding that leftsided activity can be associated with both stronger and weaker physiological downregulation of affective responses (e.g., Meyer et al., 2014a). Indeed, both the left and right hemispheres can be involved in increases and decreases of autonomic nervous system and stress hormonal responses (Kline, 2017; Miller, Crocker, Spielberg, Infantolino, \& Heller, 2013). Therefore, an explanation for these unexpected findings may require a more fine-grained analysis of neural and cognitive-emotional processes that are captured by measurements of frontal alpha asymmetry. The same is true for the finding that trauma-free controls exhibited more right-sided frontal and parietal activity at rest, which is at odds with prior findings (e.g., Rabe, Beauducel et al., 2006). Indeed, in line with the capability model of frontal asymmetry (Coan et al., 2006), these findings underline that the resting state measurements (and our "neutral" emotion condition) represent relatively uncontrolled experimental contexts. Future studies should thus attempt to replace them by conditions that better control individual or group differences on affective or motivational dimensions.

Finally, our results suggest that frontal asymmetry may be linked to reexperiencing symptoms, including intrusive memories. The theoretical link between intrusions and models of frontal asymmetry still remains elusive, since intrusive memories are typically thought to result from encoding, consolidation, or retrieval processes (Brewin, Gregory, Lipton, \& Burgess, 2010; Ehlers \& Clark, 2000; Rubin, Berntsen, \& Bohni, 2008) that make traumatic memories more or less accessible (e.g., Bisby et al., 2010; Meyer, Krans, van Ast, \& Smeets, 2016; Meyer et al., 2013). However, it is possible that the association between frontal asymmetry and intrusions is mediated by negative appraisal of intrusions, which may result from stronger withdrawal tendencies and serve as a maintaining factor of reexperiencing symptoms (Ehlers, 2010). More speculatively, direct associations could exist between frontal asymmetry and intrusions; indeed, left frontal activity has been proposed to be involved in the contextdependent activation of memories through pathways to the hippocampus (Kline, 2017; Meyer, Smeets et al., 2015). Therefore, longitudinal (and/or experimental) studies are required to establish the precise role of frontal asymmetry in reexperiencing symptoms (also see Ehring, Kleim, \& Ehlers, 2011)

The following methodological aspects should be kept in mind when interpreting our findings. First, unlike Rabe, Beauducel et al. (2006), we used resting state EEG as a baseline for activation asymmetry scores rather than the neutral condition, based on the observed group effects in frontal 
asymmetry (see Figure 3). Technically, this means that our baseline condition differed from the emotional conditions in recording length ( $8 \mathrm{~min}$ vs. $2 \mathrm{~min}$ ). This ensures high reliability and trait specificity of the baseline condition (Hagemann, 2004). At the same time, the emotion induction periods lasted 2 min each (i.e., twice as long as in Rabe, Beauducel et al., 2006), balancing the need for measurement reliability with the possibility that asymmetric activations are dynamic and short lived. Note, for instance, that shorter recording periods have been associated with larger effects in adults with anxiety or depression (Thibodeau et al., 2006). A potential limitation of this approach is that baseline and emotion induction phases had different instructional contexts, with less control over motivational states during rest. Therefore, it remains to be investigated whether our recording parameters and conditions are optimal to detect effects related to PTSD.

Second, we selected a trauma-related picture for each participant individually. Therefore, it is possible that we were more successful at activating traumatic memories for some participants than for others, which may have introduced unwanted variance and have overshadowed potential effects. However, since PTSD is characterized by poor stimulus discrimination and by a wide range of environmental stimuli that can easily trigger reexperiencing symptoms (Ehlers \& Clark, 2000), it is likely that our emotion provocation task was able to induce more trauma-specific reexperiencing symptoms in those participants who also display more PTSD symptoms in daily life. Moreover, on average, all traumaexposed individuals indicated that the picture strongly reminded them of their own traumatic experience. Third, it must be noted that we only used one stimulus for each emotion category (e.g., a barking dog for negative emotions), which limits the generalizability of our findings to the specific emotions that were induced. Relatedly, it is important to keep in mind that the comparison among emotional conditions was exploratory and still requires further replication.

Finally, replication is also warranted due to the limitations imposed by our sample size. That is, we found several relatively large effects in the $r=.41$ to .57 range (which are comparable to prior findings; e.g., Rabe, Beauducel et al., 2006), while somewhat smaller effects may have gone undetected due to limited statistical power (e.g., see the emerging trends in Table 4). This argument is especially relevant for our analyses on the time course of affect levels following everyday intrusions, which only included a subset of the participants. For ethical reasons, we allowed our participants to omit the affect grids on the smartphone when this would be experienced as too burdensome. As a result, the measured responses might represent only relatively mild symptoms, and we could use only a proportion of our participants in these analyses. Thus, the question whether frontal asymmetry might affect the time course of affective responding to trauma memories remains to be investigated further in future studies.

\section{1 | Implications and conclusions}

The present study aligns with an emerging consensus in the literature that frontal asymmetry is especially informative about individual differences in psychopathology when measured in response to an emotional provocation (Allen \& Reznik, 2015; Coan et al., 2006). Specifically, this implies that future studies into the role of frontal asymmetry in PTSD should include measurements during symptom provocation. Furthermore, on a methodological level, our study has demonstrated the benefits of including ambulatory measures to capture PTSD-specific reexperiencing symptoms, and of including a scale that measures symptom overreporting tendencies to ensure the validity of all other assessments.

Our findings suggest that state-dependent changes in frontal asymmetry could eventually serve as a biological marker of PTSD symptoms. While replication is still warranted, practical implications can be envisioned. For instance, a next step would be to investigate whether frontal activation asymmetry during an emotional provocation may serve as a predictor of the development of PTSD symptoms in individuals who have just experienced a psychological trauma. Furthermore, research should address the question of how the assessment of frontal asymmetry can be optimized in such a way that it can be used for diagnostic purposes, or to monitor treatment progress. Furthermore, our results can inspire neuromodulation studies, where frontal activation asymmetry could be a promising target. For instance, in EEG neurofeedback, parameters of ongoing brain activity are used as the basis for real-time feedback to the participant, who can thereby learn to selfregulate their own brain activity. Indeed, neurofeedback has already been used to train frontal asymmetry at rest (Allen, Harmon-Jones, \& Cavender, 2001; Peeters, Ronner, Bodar, van Os, \& Lousberg, 2014; Quaedflieg et al., 2016). Importantly, based on our results, it appears particularly promising to apply neurofeedback for PTSD patients during a symptom provocation condition (e.g., while viewing a negative trauma-related picture), rather than at rest. Finally, studying frontal activation asymmetry in response to symptom provocation might also advance our theoretical understanding of PTSD (Meyer, Smeets et al., 2015). To this end, it will be crucial to combine neuroimaging methods to elucidate the neural underpinnings of asymmetric brain activity during symptomatic states, for instance, by combining EEG with fMRI in varying motivational contexts (e.g., see Gorka, Phan, \& Shankman, 2015). That way, models of asymmetry can be updated and serve to inform neuropsychological models of PTSD. 


\section{ACKNOWLEDGMENTS}

We are especially thankful to Brigit Lok, Annie Hendriks, and Iris Nijssen for their help in the screening process and in recruiting participants, and to Michiel Vestjens for implementing the ambulatory assessments with smartphones.

\section{REFERENCES}

Allen, J. J. B., Coan, J. A., \& Nazarian, M. (2004). Issues and assumptions on the road from raw signals to metrics of frontal EEG asymmetry in emotion. Biological Psychology, 67, 183-218. doi:10. 1016/j.biopsycho.2004.03.007

Allen, J. J. B., Harmon-Jones, E., \& Cavender, J. H. (2001). Manipulation of frontal EEG asymmetry through biofeedback alters self-reported emotional responses and facial EMG. Psychophysiology, 38, 685-693. doi:10.1111/1469-8986. 3840685

Allen, J. J. B., \& Reznik, S. J. (2015). Frontal EEG asymmetry as a promising marker of depression vulnerability: Summary and methodological considerations. Current Opinion in Psychology, 4, 93-97. doi:10.1016/j.copsyc.2014.12.017

American Electroencephalographic Society. (1994). Guideline thirteen: Guidelines for standard electrode position nomenclature. Journal of Clinical Neurophysiology, 11, 111-113. doi:10.10 97/00004691-199401000-00014

American Psychiatric Association. (2000). Diagnostic and Statistical Manual of Mental Disorders: DSM-IV, Text Revision. Washington, DC: Author.

American Psychiatric Association. (2013). Diagnostic and statistical manual of mental disorders (5th ed.). Arlington, VA: Author.

Beck, A., Steer, R., \& Brown, G. (1996). Manual for the BDI-II. San Antonio, TX: Psychological Corporation.

Bisby, J. A., King, J. A., Brewin, C. R., Burgess, N., \& Curran, H. V. (2010). Acute effects of alcohol on intrusive memory development and viewpoint dependence in spatial memory support a dual representation model. Biological Psychiatry, 68, 280-286. doi:10.1016/j. biopsych.2010.01.010

Blanchard, E. B., Jones-Alexander, J., Buckley, T. C., \& Forneris, C. A. (1996). Psychometric properties of the PTSD checklist (PCL). Behaviour Research and Therapy, 34, 669-673. doi:10.1016/0005-7967(96)00033-2

Boulet, J., \& Boss, M. W. (1991). Reliability and validity of the Brief Symptom Inventory. Psychological Assessment, 3, 433-437. doi: 10.1037/1040-3590.3.3.433

Brewin, C. R. (2011). The nature and significance of memory disturbance in posttraumatic stress disorder. Annual Review of Clinical Psychology, 7, 203-227. doi:10.1146/annurev-clinpsy-032210104544

Brewin, C. R. (2015). Re-experiencing traumatic events in PTSD: New avenues in research on intrusive memories and flashbacks. European Journal of Psychotraumatology, 6. doi:10.3402/ejpt. v6.27180

Brewin, C. R., Andrews, B., \& Valentine, J. D. (2000). Meta-analysis of risk factors for posttraumatic stress disorder in trauma-exposed adults. Journal of Consulting and Clinical Psychology, 68, 748766. doi:10.1037/0022-006X.68.5.748
Brewin, C. R., Gregory, J. D., Lipton, M., \& Burgess, N. (2010). Intrusive images in psychological disorders: Characteristics, neural mechanisms, and treatment implications. Psychological Review, 117, 210-232. doi:10.1037/a0018113

Bruder, G. E., Fong, R., Tenke, C. E., Leite, P., Towey, J. P., Stewart, J. E., ... Quitkin, F. M. (1997). Regional brain asymmetries in major depression with or without an anxiety disorder: A quantitative electroencephalographic study. Biological Psychiatry, 41, 939-948. doi: 10.1016/s0006-3223(96)00260-0

Bryant, R. A., O’Donnell, M. L., Creamer, M., McFarlane, A. C., \& Silove, D. (2011). Posttraumatic intrusive symptoms across psychiatric disorders. Journal of Psychiatric Research, 45, 842-847. doi:10.1016/j.jpsychires.2010.11.012

Chun, C. A. (2016). The expression of posttraumatic stress symptoms in daily life: A review of experience sampling methodology and daily diary studies. Journal of Psychopathology and Behavioral Assessment, 1-15. doi:10.1007/s10862-016-9540-3

Clohessy, S., \& Ehlers, A. (1999). PTSD symptoms, response to intrusive memories and coping in ambulance service workers. British Journal of Clinical Psychology, 38, 251-265. doi:10.1348/ 014466599162836

Coan, J. A., \& Allen, J. J. B. (2004). Frontal EEG asymmetry as a moderator and mediator of emotion. Biological Psychology, 67, 7-49. doi:10.1016/j.biopsycho.2004.03.002

Coan, J. A., Allen, J. J. B., \& McKnight, P. E. (2006). A capability model of individual differences in frontal EEG asymmetry. Biological Psychology, 72, 198-207. doi:10.1016/j.biopsycho.2005.10.003

Dandachi-FitzGerald, B., Ponds, R. W., Peters, M. J., \& Merckelbach, H. (2011). Cognitive underperformance and symptom overreporting in a mixed psychiatric sample. Clinical Neuropsychologist, 25, 812-828. doi:10.1080/13854046.2011.583280

Davidson, R. J., Marshall, J. R., Tomarken, A. J., \& Henriques, J. B. (2000). While a phobic waits: Regional brain electrical and autonomic activity in social phobics during anticipation of public speaking. Biological Psychiatry, 47, 85-95. doi:10.1016/S00063223(99)00222-X

Doppelmayr, M., Klimesch, W., Pachinger, T., \& Ripper, B. (1998). Individual differences in brain dynamics: Important implications for the calculation of event-related band power. Biological Cybernetics, 79, 49-57. doi:10.1007/s004220050457

Ehlers, A. (2010). Understanding and treating unwanted trauma memories in posttraumatic stress disorder. Zeitschrift Fur Psychologie-Journal of Psychology, 218, 141-145. doi:10.1027/0044-3409/a000021

Ehlers, A., \& Clark, D. M. (2000). A cognitive model of posttraumatic stress disorder. Behaviour Research and Therapy, 38, 319345. doi:10.1016/S0005-7967(99)00123-0

Ehring, T., Kleim, B., \& Ehlers, A. (2011). Combining clinical studies and analogue experiments to investigate cognitive mechanisms in posttraumatic stress disorder. International Journal of Cognitive Therapy, 4, 165-177. doi:10.1521/ijct.2011.4.2.165

First, M. B., Spitzer, R. L., Gibbon, M., \& Williams, J. B. W. (2002). Structured Clinical Interview for DSM-IV-TR Axis I Disorders. New York, NY: Biometrics Research, New York State Psychiatric Institute.

Foa, E. B., Riggs, D. S., Dancu, C. V., \& Rothbaum, B. O. (1993). Reliability and validity of a brief instrument for assessing post- 
traumatic stress disorder. Journal of Traumatic Stress, 6, 459473. doi:10.1002/jts. 2490060405

Forbes, D., Elhai, J. D., Lockwood, E., Creamer, M., Frueh, B. C., \& Magruder, K. M. (2012). The structure of posttraumatic psychopathology in veterans attending primary care. Journal of Anxiety Disorders, 26, 95-101. doi:10.1016/j.janxdis.2011.09.004

Gordon, E., Palmer, D. M., \& Cooper, N. (2010). EEG alpha asymmetry in schizophrenia, depression, PTSD, panic disorder, ADHD and conduct disorder. Clinical EEG and Neuroscience, 41, 178183. doi:10.1177/155005941004100404

Gorka, S. M., Phan, K. L., \& Shankman, S. A. (2015). Convergence of EEG and fMRI measures of reward anticipation. Biological Psychology, 112, 12-19. doi:10.1016/j.biopsycho.2015.09.007

Hagemann, D. (2004). Individual differences in anterior EEG asymmetry: Methodological problems and solutions. Biological Psychology, 67, 157-182. doi:10.1016/j.biopsycho.2004.03.006

Hagemann, D., Naumann, E., Thayer, J. F., \& Bartussek, D. (2002). Does resting electroencephalograph asymmetry reflect a trait? An application of latent state-trait theory. Journal of Personality and Social Psychology, 82, 619-641. doi:10.1037//00223514.82.4.619

Harmon-Jones, E., Gable, P. A., \& Peterson, C. K. (2010). The role of asymmetric frontal cortical activity in emotion-related phenomena: A review and update. Biological Psychology, 84, 451-462. doi:10.1016/j.biopsycho.2009.08.010

Heller, W., Nitschke, J. B., Etienne, M. A., \& Miller, G. A. (1997). Patterns of regional brain activity differentiate types of anxiety. Journal of Abnormal Psychology, 106, 376-385. doi:10.1037//0021-843x. 106.3.376

Holmes, E. A., Brewin, C. R., \& Hennessy, R. G. (2004). Trauma films, information processing, and intrusive memory development. Journal of Experimental Psychology-General, 133, 3-22. doi:10.1037/00963445.133.1.3

Keil, A., Debener, S., Gratton, G., Junghöfer, M., Kappenman, E. S., Luck, S. J., ... Yee, C. M. (2014). Committee report: Publication guidelines and recommendations for studies using electroencephalography and magnetoencephalography. Psychophysiology, 51, 1-21. doi:10.1111/psyp.12147

Kessler, R. C., Sonnega, A., Bromet, E., Hughes, M., \& Nelson, C. B. (1995). Posttraumatic stress disorder in the National Comorbidity Survey. Archives of General Psychiatry, 52, 1048-1060. doi: 10.1001/archpsyc.1995.03950240066012

Klimesch, W. (1999). EEG alpha and theta oscillations reflect cognitive and memory performance: A review and analysis. Brain Research Reviews, 29, 169-195. doi:10.1016/s0165-0173(98) 00056-3

Kline, J. P. (2017). Beyond the happy hemisphere hypothesis: Toward an integrated theory of frontal asymmetry in cognition, emotion, health, and psychophysiology. Psychophysiology, this issue. $\cdots$

Koslov, K., Mendes, W. B., Pajtas, P. E., \& Pizzagalli, D. A. (2011). Asymmetry in resting intracortical activity as a buffer to social threat. Psychological Science, 22, 641-649. doi:10.1177/ 0956797611403156

Lang, P. J., Bradley, M. M., \& Cuthbert, B. N. (2005). International Affective Picture System (IAPS): Instruction Manual and Affective
Ratings. Technical Report A-6. Gainesville, FL: University of Florida.

McNally, R. J., \& Robinaugh, D. J. (2011). Risk factors and posttraumatic stress disorder: Are they especially predictive following exposure to less severe stressors? Depression and Anxiety, 28, 1091-1096. doi:10.1002/da.20867

Merckelbach, H., \& Smith, G. P. (2003). Diagnostic accuracy of the Structured Inventory of Malingered Symptomatology (SIMS) in detecting instructed malingering. Archives of Clinical Neuropsychology, 18, 145-152. doi:10.1016/S0887-6177(01)00191-3

Meyer, T., Krans, J., van Ast, V., \& Smeets, T. (2016). Visuospatial context learning and configuration learning is associated with analogue traumatic intrusions. Journal of Behavior Therapy and Experimental Psychiatry, 54, 120-127. doi:10.1016/j.jbtep.2016.07.010

Meyer, T., Otgaar, H., \& Smeets, T. (2015). Flashbacks, intrusions, mind-wandering - Instances of an involuntary memory spectrum: A commentary on Takarangi, Strange, and Lindsay (2014). Consciousness and Cognition, 33, 24-29. doi:10.1016/j. concog.2014.11.012

Meyer, T., Quaedflieg, C. W. E. M., Giesbrecht, T., Meijer, E., Abiad, S., \& Smeets, T. (2014a). Frontal EEG asymmetry as predictor of physiological responses to aversive memories. Psychophysiology, 51, 853-865. doi:10.1111/psyp.12230

Meyer, T., Quaedflieg, C. W. E. M., Giesbrecht, T., Meijer, E., Abiad, S., \& Smeets, T. (2014b). Frontal EEG asymmetry as predictor of physiological responses to aversive memories. Psychophysiology, 51, 853-865. doi:10.1111/psyp.12230

Meyer, T., Smeets, T., Giesbrecht, T., Quaedflieg, C. W. E. M., Girardelli, M. M., Mackay, G. R. N., \& Merckelbach, H. (2013). Individual differences in spatial configuration learning predict the occurrence of intrusive memories. Cognitive, Affective, \& Behavioral Neuroscience, 13, 186-196. doi:10.3758/s13415-012-0123-9

Meyer, T., Smeets, T., Giesbrecht, T., Quaedflieg, C. W. E. M., Smulders, F. T. Y., Meijer, E. H., \& Merckelbach, H. L. G. J. (2015). The role of frontal EEG asymmetry in post-traumatic stress disorder. Biological Psychology, 108, 62-77. doi:10.1016/j. biopsycho.2015.03.018

Miller, G. A., Crocker, L. D., Spielberg, J. M., Infantolino, Z. P., \& Heller, W. (2013). Issues in localization of brain function: The case of lateralized frontal cortex in cognition, emotion, and psychopathology. Frontiers in Integrative Neuroscience, 7. doi: 10.3389/fnint.2013.00002

Nitschke, J. B., Heller, W., Palmieri, P. A., \& Miller, G. A. (1999). Contrasting patterns of brain activity in anxious apprehension and anxious arousal. Psychophysiology, 36, 628-637. doi:10. 1111/1469-8986.3650628

Nusslock, R., Walden, K., \& Harmon-Jones, E. (2015). Asymmetrical frontal cortical activity associated with differential risk for mood and anxiety disorder symptoms: An RDoC perspective. International Journal of Psychophysiology, 98, 249-261. doi:10.1016/j. ijpsycho.2015.06.004

Oldfield, R. C. (1971). The assessment and analysis of handedness: The Edinburgh inventory. Neuropsychologia, 9, 97-113. doi: 10.1016/0028-3932(71)90067-4

Peeters, F., Ronner, J., Bodar, L., van Os, J., \& Lousberg, R. (2014). Validation of a neurofeedback paradigm: Manipulating frontal 
EEG alpha-activity and its impact on mood. International Journal of Psychophysiology, 93, 116-120. doi:10.1016/j. ijpsycho.2013.06.010

Pfurtscheller, G., Stancak, A., \& Neuper, C. (1996). Event-related synchronization (ERS) in the alpha band-An electrophysiological correlate of cortical idling: A review. International Journal of Psychophysiology, 24, 39-46. doi:10.1016/s0167-8760(96)00066-9

Pivik, R. T., Broughton, R. J., Coppola, R., Davidson, R. J., Fox, N., \& Nuwer, M. R. (1993). Guidelines for the recording and quantitative analysis of electroencephalographic activity in research contexts. Psychophysiology, 30, 547-558. doi:10.1111/j.14698986.1993.tb02081.x

Quaedflieg, C. W. E. M., Meyer, T., Smulders, F. T. Y., \& Smeets, T. (2015). The functional role of individual-alpha based frontal asymmetry in stress responding. Biological Psychology, 104, 7581. doi:10.1016/j.biopsycho.2014.11.014

Quaedflieg, C. W. E. M., Smulders, F. T. Y., Meyer, T., Peeters, F., Merckelbach, H., \& Smeets, T. (2016). The validity of individual frontal alpha asymmetry EEG neurofeedback. Social Cognitive and Affective Neuroscience, 11, 33-43. doi:10.1093/scan/nsv090

Rabe, S., Beauducel, A., Zöllner, T., Maercker, A., \& Karl, A. (2006). Regional brain electrical activity in posttraumatic stress disorder after motor vehicle accident. Journal of Abnormal Psychology, 115, 687-698. doi:10.1037/0021-843x.115.4.687

Rabe, S., Zöllner, T., Beauducel, A., Maercker, A., \& Karl, A. (2008). Changes in brain electrical activity after cognitive behavioral therapy for posttraumatic stress disorder in patients injured in motor vehicle accidents. Psychosomatic Medicine, 70, 13-19. doi:10.1097/PSY. 0b013e31815aa325

Rabe, S., Zöllner, T., Maercker, A., \& Karl, A. (2006). Neural correlates of posttraumatic growth after severe motor vehicle accidents. Journal of Consulting and Clinical Psychology, 74, 880-886. doi: 10.1037/0022-006x.74.5.880

Reid, S. A., Duke, L. M., \& Allen, J. J. B. (1998). Resting frontal electroencephalographic asymmetry in depression: Inconsistencies suggest the need to identify mediating factors. Psychophysiology, 35, 389-404. doi:10.1111/1469-8986.3540389

Rivest, L. P. (1994). Statistical properties of Winsorized means for skewed distributions. Biometrika, 81, 373-383. doi:10.1093/biomet/81.2.373

Rosen, G. M., \& Lilienfeld, S. O. (2008). Posttraumatic stress disorder: An empirical evaluation of core assumptions. Clinical Psychology Review, 28, 837-868. doi:10.1016/j.cpr.2007.12.002

Rubin, D. C., Berntsen, D., \& Bohni, M. K. (2008). Memory-based model of posttraumatic stress disorder: Evaluating basic assumptions underlying the PTSD diagnosis. Psychological Review, 115, 985-1011. doi:10.1037/a0013397

Rubin, D. C., Boals, A., \& Berntsen, D. (2008). Memory in posttraumatic stress disorder: Properties of voluntary and involuntary, traumatic and nontraumatic autobiographical memories in people with and without posttraumatic stress disorder symptoms. Journal of Experimental Psychology-General, 137, 591-614. doi:10.1037/ a0013165

Russell, J. A., Weiss, A., \& Mendelsohn, G. A. (1989). Affect grid: A single-item scale of pleasure and arousal. Journal of Personality and Social Psychology, 57, 493-502. doi:10.1037/0022-3514.57.3.493
Schmidt, U. (2015). A plea for symptom-based research in psychiatry. European Journal of Psychotraumatology, 6. doi:10.3402/ejpt.v6. 27660

Sheehan, D. V., Lecrubier, Y., Sheehan, K. H., Amorim, P., Janavs, J., Weiller, E., ... Dunbar, G. C. (1998). The MiniInternational Neuropsychiatric Interview (M.I.N.I): The development and validation of a structured diagnostic psychiatric interview for DSM-IV and ICD-10. Journal of Clinical Psychiatry, $59,22-33$.

Smets, J., Wessel, I., Schreurs, E., \& Raes, F. (2012). The interplay between rumination and intrusions in the prediction of concurrent and prospective depressive symptoms in two nonclinical samples. Psychological Record, 62, 777-787.

Smith, G. P., \& Burger, G. K. (1997). Detection of malingering: Validation of the Structured Inventory of Malingered Symptomatology (SIMS). Journal of the American Academy of Psychiatry and the Law Online, 25, 183-189.

Spielberger, C. D. (1983). Manual for the State-Trait Anxiety Inventor STAI (Form Y). Palo Alto, CA: Consulting Psychologists Press.

Steil, R., \& Ehlers, A. (2000). Dysfunctional meaning of posttraumatic intrusions in chronic PTSD. Behaviour Research and Therapy, 38, 537-558. doi:10.1016/s0005-7967(99)00069-8

Stewart, J. L., Coan, J. A., Towers, D. N., \& Allen, J. J. (2014). Resting and task-elicited prefrontal EEG alpha asymmetry in depression: Support for the capability model. Psychophysiology, 51(5) 446-455. doi:10.1111/psyp.12191

Stewart, J. L., Coan, J. A., Towers, D. N., \& Allen, J. J. B. (2011). Frontal EEG asymmetry during emotional challenge differentiates individuals with and without lifetime major depressive disorder. Journal of Affective Disorders, 129, 167-174. doi:10.1016/j. jad.2010.08.029

Thibodeau, R., Jorgensen, R. S., \& Kim, S. (2006). Depression, anxiety, and resting frontal EEG asymmetry: A meta-analytic review. Journal of Abnormal Psychology, 115, 715-729. doi:10. 1037/0021-843x.115.4.715

Tomarken, A. J., Davidson, R. J., Wheeler, R. E., \& Doss, R. C. (1992). Individual differences in anterior brain asymmetry and fundamental dimensions of emotion. Journal of Personality and Social Psychology, 62, 676-687. doi:10.1037/0022-3514.62.4.676

Tomarken, A. J., Davidson, R. J., Wheeler, R. E., \& Kinney, L. (1992). Psychometric properties of resting anterior EEG asymmetry: Temporal stability and internal consistency. Psychophysiology, 29, 576-592. doi:10.1111/j.1469-8986.1992.tb02034.x

Towers, D. N., \& Allen, J. J. B. (2009). A better estimate of the internal consistency reliability of frontal EEG asymmetry scores. Psychophysiology, 46, 132-142. doi:10.1111/j.1469-8986.2008.00759.x

Urry, H. L., Nitschke, J. B., Dolski, I., Jackson, D. C., Dalton, K. M., Mueller, C. J., ... Davidson, R. J. (2004). Making a life worth living-Neural correlates of well-being. Psychological Science, 15, 367-372. doi:10.1111/j.0956-7976.2004.00686.x

Velo, J. R., Stewart, J. L., Hasler, B. P., Towers, D. N., \& Allen, J. J. B. (2012). Should it matter when we record? Time of year and time of day as factors influencing frontal EEG asymmetry. Biological Psychology, 91, 283-291. doi:10.1016/j.biopsycho.2012.06.010

Wacker, J., Chavanon, M. L., Leue, A., \& Stemmler, G. (2008). Is running away right? The behavioral activation-behavioral inhibition 
model of anterior asymmetry. Emotion, 8, 232-249. doi:10. 1037/1528-3542.8.2.232

Wahbeh, H., \& Oken, B. S. (2013). Peak high-frequency HRV and peak alpha frequency higher in PTSD. Applied Psychophysiology and Biofeedback, 38, 57-69. doi:10.1007/s10484-012-9208-z

Watson, D., Clark, L. A., \& Tellegen, A. (1988). Development and validation of brief measures of positive and negative affect: The PANAS scales. Journal of Personality and Social Psychology, 54, 1063-1070. doi:10.1037/0022-3514.54.6.1063

Wiedemann, G., Pauli, P., Dengler, W., Lutzenberger, W., Birbaumer, N., \& Buchkremer, G. (1999). Frontal brain asymmetry as a biological substrate of emotions in patients with panic disorders. Archives of General Psychiatry, 56, 78-84. doi:10.1001/ archpsyc.56.1.78

Zoellner, L. A., Pruitt, L. D., Farach, F. J., \& Jun, J. J. (2014). Understanding heterogeneity in PTSD: Fear, dysphoria, and distress. Depression and Anxiety., 31,97-106. doi:10.1002/da.22133

\section{SUPPORTING INFORMATION}

Additional supporting information may be found in the supporting information tab for this article.

\section{Table S1}

Table S2

Table S3

How to cite this article: Meyer T, Quaedflieg CWEM, Weijland K, Schruers K, Merckelbach H, Smeets T. Frontal EEG asymmetry during symptom provocation predicts subjective responses to intrusions in survivors with and without PTSD. Psychophysiology. 2018;55: e12779. https://doi.org/10.1111/psyp.12779 